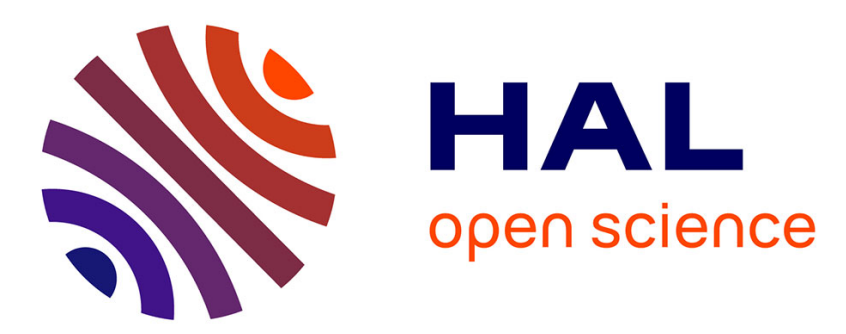

\title{
Visnu mitrés et réseaux marchands en Asie du Sud-Est : nouvelles données archéologiques sur le Ier millénaire apr. J.-C.
}

\author{
Nadine Dalsheimer, Pierre-Yves Manguin
}

\section{- To cite this version:}

Nadine Dalsheimer, Pierre-Yves Manguin. Visnu mitrés et réseaux marchands en Asie du SudEst: nouvelles données archéologiques sur le Ier millénaire apr. J.-C.. Bulletin de l'Ecole française d'Extrême-Orient, 1998, 85 (1), pp.87 - 123. 10.3406/befeo.1998.2545 . halshs-02512605

\section{HAL Id: halshs-02512605 \\ https://shs.hal.science/halshs-02512605}

Submitted on 19 Mar 2020

HAL is a multi-disciplinary open access archive for the deposit and dissemination of scientific research documents, whether they are published or not. The documents may come from teaching and research institutions in France or abroad, or from public or private research centers.
L'archive ouverte pluridisciplinaire HAL, est destinée au dépôt et à la diffusion de documents scientifiques de niveau recherche, publiés ou non, émanant des établissements d'enseignement et de recherche français ou étrangers, des laboratoires publics ou privés. 


\title{
Visnu mitrés et réseaux marchands en Asie du Sud-Est :
} nouvelles données archéologiques sur le ler millénaire apr. J.-C. Nadine Dalsheimer, Pierre-Yves Manguin

\begin{abstract}
Résumé
Abstract Mitred Visnus and trade networks in Southeast Asia: new archaeological data on the 1st millennium A.D. New archaeological research carried out on three different fronts (history of early Cambodian art, excavations at Kota Kapur, South Sumatra, and at Cibuaya, West Java) revealed hitherto unsuspected links between a series of sites that have at least one common characteristic : they all produced statues of Visnu wearing a mitre and a long robe, that can be grouped on stylistic grounds into one single family. The chronology of this pan- Southeast Asian family is reconsidered here in the light of the new finds : their anteriority to the Early Khmer art style of Phnom Da is demonstrated ; all of its pieces can now be securely dated from the early Vth to the early VIlth centuries. On the Indochinese peninsula, in what is now Cambodia and Viêt Nam, they are therefore associated with the last two centuries of the Funan polity, rather than with Early Khmer art forms. The central and pioneer role of the Malay peninsula, where the earliest statues (those closest to Indian prototypes) were found, is however emphasized in the study. Rather than to one specific « national » polity, the production of this family of statues is therefore associated with a trade network regrouping a number of archaeological sites on the Western maritime façade of Southeast Asia. Finally, this network is identified as being of Vaisnava obedience. The role played by this Brahmanical sect in the Indianization of Southeast Asia during the period considered is then compared to that played by Buddhism.
\end{abstract}

\section{Citer ce document / Cite this document :}

Dalsheimer Nadine, Manguin Pierre-Yves. Visnu mitrés et réseaux marchands en Asie du Sud-Est : nouvelles données archéologiques sur le ler millénaire apr. J.-C.. In: Bulletin de l'Ecole française d'Extrême-Orient. Tome 85, 1998. pp. 87123;

doi : https://doi.org/10.3406/befeo.1998.2545

https://www.persee.fr/doc/befeo_0336-1519_1998_num_85_1_2545

Fichier pdf généré le 08/11/2019 


\title{
Viṣnu mitrés et réseaux marchands en Asie du Sud-Est : nouvelles données archéologiques sur le $\mathrm{I}^{\text {er }}$ millénaire apr. J.-C.
}

\author{
Nadine DALSHEIMER et Pierre-Yves MANGUIN
}

La famille stylistique dite « des Visnu mitrés » a fait couler beaucoup d'encre chez les historiens de l'art depuis qu'elle a été identifiée dans les collections du Cambodge et de la Thaïlande péninsulaire au début de ce siècle. Pierre Dupont, le premier, a tenté d'en offrir une approche systématique, à partir surtout des pièces trouvées au Cambodge et au Viêt Nam ${ }^{1}$. Il a ainsi permis de rassembler en une même famille une série de statues géographiquement éparses, mais présentant d'indéniables caractéristiques iconographiques et stylistiques communes : toutes représentent des Viṣnu à quatre bras, à la poitrine découverte, portant une robe longue nouée sur les hanches et coiffées d'une mitre. P. Dupont considérait ces images comme un groupe secondaire du Zhenla, dont il situait la production au début du VIIe siècle ${ }^{2}$.

Pour sa part, Stanley O'Connor a consacré en 1972 une étude fondamentale aux pièces thaillandaises : on doit surtout lui attribuer le mérite d'avoir reconnu le premier les prototypes indiens des pièces les plus anciennes, retrouvés dans la statuaire de Mathurā datant des IIIc et IVc siècles apr. J.-C. et, à la suite de celles-ci, dans la statuaire du IV $\mathrm{IV}^{-} \mathrm{V}^{\mathrm{e}}$ siècle trouvée à Yeleśwaram, un site près de Nāgārjunakoṇ̣a, dans l'Andhra Pradesh. Il a donc pu ainsi établir une première chronologie fiable de ces statues, entre

1. Dans ses études pionnières de 1941 et de 1951 , et à nouveau dans son grand ouvrage consacré à La statuaire préangkorienne (1955). On trouvera les premières remarques de $\mathrm{H}$. Parmentier sur ces pièces rassemblées dans son Art khmer primitif (1927, 2 vol.). J. Boisselier les passe bien entendu en revue dans son étude d'ensemble sur La statuaire khmère et son évolution (1955). On se reportera aux divers chapitres de L'archéologie du delta du Mékong de Louis Malleret (1959-1963) pour un inventaire, alors exhaustif, des pièces trouvées sur le territoire vietnamien. Les productions artistiques découvertes dans la basse vallée et le delta du Mékong (aujourd'hui sur les territoires du Cambodge et du Viêt Nam) ont le plus souvent été désignées par les termes « d'art khmer primitif », de « premier art khmer » ou encore d'art « préangkorien » (cette dernière expression étant de loin la plus populaire, en particulier parmi les collectionneurs). Toutes ces expressions présupposent qu'elles ont été créées par le groupe ethnique khmer. Si cette proposition est avérée pour l'immense majorité des productions de la région, qui est postérieure au VIc siècle, elle n'en est pas moins infondée, jusqu'à preuve du contraire, pour les productions des $\mathrm{V}^{\mathrm{e}}$ et $\mathrm{VI}^{\mathrm{e}}$ siècles (ou peut-être même plus tôt encore pour la statuaire en bois), qui ne peuvent être attribuées qu'à l'État que l'on nomme faute de mieux le Funan. Or, à ce jour, rien ne permet de déterminer quel était le ou les groupe(s) ethnique(s) à l'origine de ce premier grand État de la vallée du Mékong. Dans la mesure du possible, on évitera donc dans cet article de parler d'art « khmer » ou « préangkorien » pour les premières productions de la région.

2. Dupont 1941,1955 , p. 123-124. Les premiers doutes sur la datation tardive de Dupont pour ces pièces furent émis par P. S. Rawson dans le compte rendu qu'il fit de l'ouvrage de P. Dupont (dans le numéro du printemps 1957 de Oriental Art). 
une date « qui ne peut être plus tardive que 400 » pour le Viṣnu de Chaiya - proche de ces prototypes et considéré comme le Viṣnu le plus ancien d'Asie du Sud-Est - et les $\mathrm{VII}^{\mathrm{c}}$ et VIII ${ }^{\mathrm{c}}$ siècles, pendant lesquels apparaissent des statues provenant d'ateliers locaux qui maîtrisent désormais parfaitement ce moyen d'expression ${ }^{3}$. Il inverse en quelque sorte les deux extrêmes de la séquence chronologique proposée par Dupont (et réaffirmée par la suite par Boisselier dans ses premiers ouvrages) : les pièces que ces derniers considéraient comme des productions locales maladroites - donc tardives ou aberrantes - deviennent les pièces les plus anciennes, car les plus proches de leurs prototypes indiens ; les pièces esthétiquement élaborées, comme le Viṣnu de Takuapa, sont désormais considérées comme des productions locales, aboutissement d'une technique mieux maîtrisée.

La grande majorité des sculptures de cette famille provient des deux régions étudiées en priorité par Dupont et O'Connor : d'une part la basse vallée et le delta du Mékong ; d'autre part les deux rives de l'isthme de la péninsule Malaise, du côté thailandais de la frontière (les sites de Kedah, du côté malaisien de la frontière, pourtant riches en vestiges bouddhiques dès les environs du ve siècle, n'ont livré à ce jour aucune sculpture brahmanique du premier millénaire apr. J.-C. ).

Une première pièce extérieure à ces deux régions fut publiée en 1937 par Willem Stutterheim : un petit buste, sans ses bras, en provenance du site de Kota Kapur, sur l'île de Bangka (Sumatra-Sud), près du lieu où l'on avait découvert un demi-siècle auparavant une inscription de 686 (que George Codès devait attribuer à la période de formation du royaume de Śrivijaya) ${ }^{4}$. Le savant hollandais reconnut bien les rapports de cette petite statue avec les pièces plus septentrionales, encore mal connues ; il l'associa aux premiers temps de l'État de Sriwijaya, comme l'inscription dont elle était voisine. Mais cette découverte restait isolée, le site de sa découverte obscur, la période troublée : son importance passa alors largement inaperçue. Setyawati Suleiman la publia à nouveau en 1980 : avec son intuition habituelle, mais sans plus élaborer, elle remarqua des similitudes avec les statues de Cibuaya et plaça cette pièce au VIc siècle en la rattachant à une pratique de l'hindouïsme antérieure à Sriwijaya ${ }^{5}$.

Trois nouvelles pièces ont été par la suite trouvées à Cibuaya, un site de la baie de Jakarta, en 1952,1957 et $1975^{6}$. La première d'entre elles fut étudiée par Jean Boisselier dès 1959, qui la décrivit en détail et ne lui ménagea pas les appréciations désobligeantes : pièce «aberrante », « esthétiquement médiocre », produit de la technique «dénaturée » ou d'un sculpteur «inexpérimenté », dont la parure était « d'une pauvreté si exceptionnelle » qu'elle ne pouvait être qu'un « souvenir abâtardi ». Il en conclut donc, comme pour le Viṣnu de Chaiya auquel il comparait cette image, à une « régression", et en fit même « le stade final d'une dégradation » (fig. 15). L'ensemble des statues a fait depuis l'objet d'analyses par divers auteurs indonésiens ; pas plus que J. Boisselier, ceux-ci n'ont reconnu les prototypes indiens anciens de ces trois pièces : tous en ont donc fait des statues tardives, rapprochées plutôt de l'art

3. S. J. O'Connor 1972 (p. 39 pour la citation). Sur les pièces thaïlandaises, on consultera aussi avec profit Piriya Krairiksh 1980.

4. W.F. Stutterheim 1937. Dans cet article, on utilisera en général l'orthographe indonésienne commune «Sriwijaya » pour l'État dont le nom apparaît dans les inscriptions en vieux malais sous la forme sansktite Srivijaya. Voir à son propos Cœdès 1918, 1930.

5. Subhadradis Diskul (éd.),1980, fig. 13, p. 14, 38. On doit déduire des remarques de Setyawati Suleiman sur cette statue de Kota Kapur qu'elle n'acceptait pas non plus la datation tardive du premier Viṣnu de Cibuaya par Jean Boisselier. Voir infra, et notre conclusion, pour une discussion plus approfondie des sites de la baie de Jakarta.

6. C'est ainsi (Cibuaya) qu'il faut orthographier ce toponyme, pour se conformer à la graphie unifiée du malais-indonésien. L'ancienne orthographe, utilisée encore chez Boisselier, est Tjibuaja. 
Pallava des VII ce VIII ${ }^{e}$ siècles ${ }^{7}$. Stanley O'Connor, dans son étude de 1972, avait pourtant déjà intégré ce premier Viṣnu de Cibuaya dans sa séquence chronologique fondée sur les pièces thaïlandaises et sur leurs prototypes indiens : il le place dans la deuxième génération des Viṣnu mitrés, avec une conque désormais haute, dans le courant du $V^{c}$ siècle (la conque, jusque là appuyée sur la hanche gauche, sera désormais toujours tenue en position haute) ${ }^{8}$.

Peu après la parution de l'étude de Stanley O'Connor, J. Boisselier accepte dans son ouvrage sur La sculpture en Thaillande la chronologie qui y est proposée et classe bien le Viṣnu de Chaiya parmi les premières images du pays. Dans une note, il admet en conséquence son « interprétation erronée » de cette statue dans son article de 1959, mais n'en tire curieusement aucune conclusion pour l'image de Cibuaya elle-même : il l'abandonne donc définitivement, avec l'autre statue trouvée entre-temps, à un VII siècle où elle ne peut qu'être le produit d'une dégradation technique ${ }^{9}$.

Des recherches récentes, menées sur trois fronts différents, nous permettent aujourd'hui d'amener une série de pièces nouvelles à ce dossier. Le catalogage systématique de la statuaire de la péninsule Indochinoise mené à l'EFEO, sous la direction de Bruno Dagens, et les études qui l'accompagnent ont d'abord permis d'appréhender sous un jour nouveau la chronologie du premier art de la région, et donc celle de ces Viṣnu mitrés. En 1994, la découverte à Kota Kapur d'un site archéologique important par une équipe conjointe du Centre national de la Recherche archéologique d'Indonésie et de l'EFEO a permis de mettre au jour quatre nouvelles statues de cette famille stylistique avec, pour la première fois, le sanctuaire qu'elles ornaient ${ }^{10}$. Enfin, des travaux indonésiens en cours sur l'ensemble des sites de la baie de Jakarta permettent aujourd'hui de mieux appréhender leur chronologie et leur place, jusqu'ici mal comprise, dans l'histoire de la région.

Il nous a donc paru bon de faire ici le point sur ces recherches nouvelles et de tenter ainsi de mieux comprendre la place de cette statuaire « mitrée », seul trait d'union tangible entre l'ensemble de ces sites encore bien mal connus de l'Asie du Sud-Est occidentale, dont tout laisse à penser qu'ils ont bien plus en commun, avant le VII e siècle, que ce que l'on a laissé entendre jusqu'ici.

7. J. Boisselier 1959 ; Sutjipto Wirjosuparto 1963 ; le troisième Viṣnu, ou le peu qu'il en reste, n'est publié à notre connaissance que dans E. Edwards McKinnon, Hasan Djafar et Soeroso 1998, p. 154, fig.5. On consultera aussi le mémoire de maîtrise inédit d'Edi Sedyawati (Artja-artja Wiṣnu dari Tjibuaja, Fakultas Sastra Universitas Indonesia, 1963) ou, plus récemment, l'article de Sri Utami Ferdinandus 1995 . S. O'Connor (1972, p. 43-44) a largement réfuté ces affinités Pallava, fondées pour l'essentiel sur les similitudes des coiffures en forme de mitre, alors que d'autres affinités étaient ignorées.

8. O'Connor 1972, p. 27.

9. Boisselier 1974, p. 71 et note 20. Les deux statues de Viṣnu de Cibuaya sont ainsi encore mentionnées dans le dernier ouvrage d'ensemble sur l'art de l'Asie du Sud-Est publié par J. Boisselier (1986), dans les premières pages du chapitre consacré à l'Indonésie.

10. Comme à Kota Kapur, des terrasses et des soubassements divers, ayant probablement supporté des édifices en matériaux légers, ont été signalés à Angkor Borei et au Phnom Da sur les sites d'où proviennent des statues de la famille des Viṣnu mitrés (Dupont 1955, p. 23). Cependant, à notre connaissance, une corrélation directe entre la statuaire et les monuments n'a jamais été établie. 


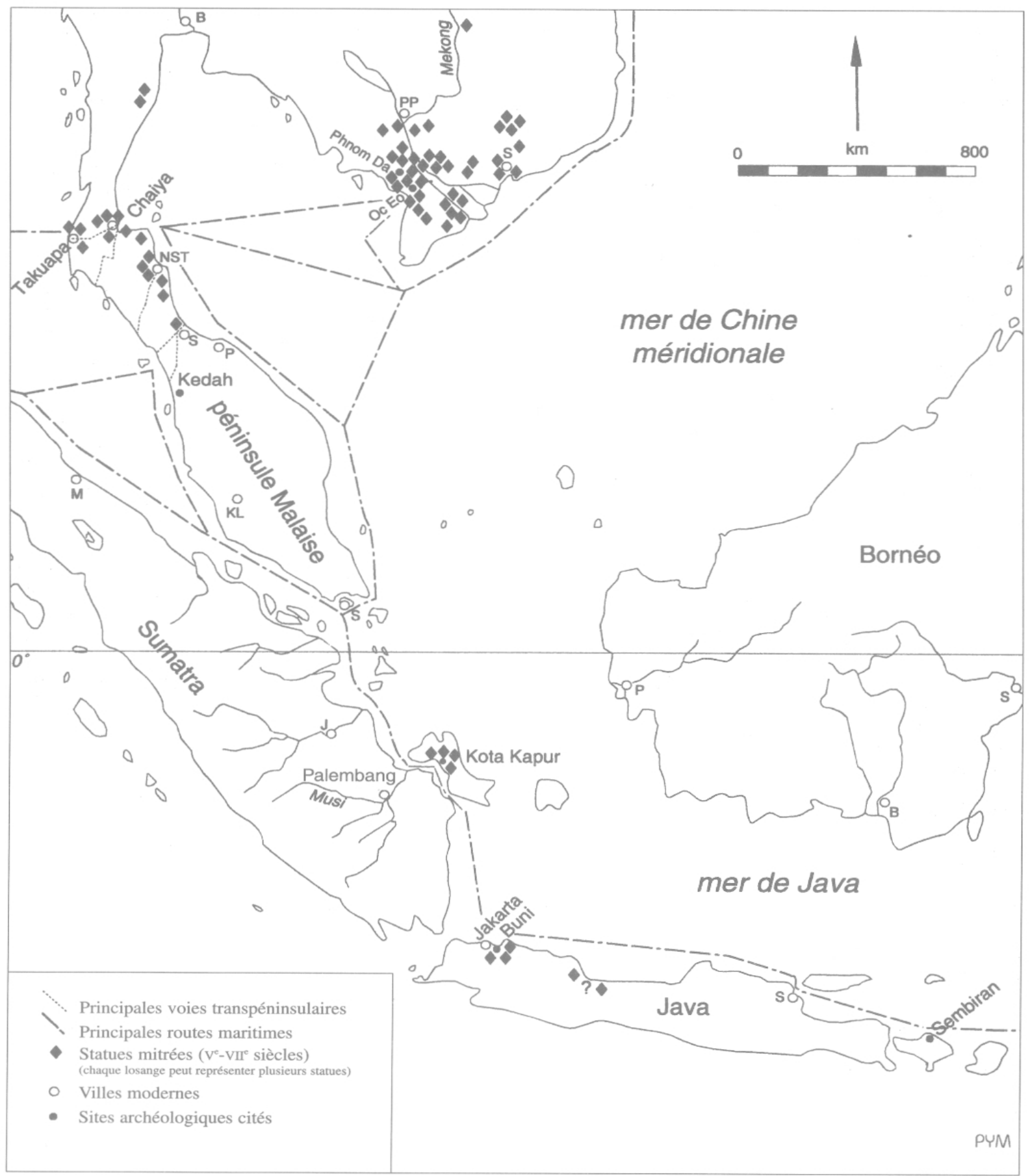

Sites à statues «mitrées » et réseaux marchands en Asie du Sud-Est ( $\mathrm{V}^{\mathrm{e}}$-VII ${ }^{\mathrm{e}}$ siècles). 


\section{La statuaire de la vallée du Mékong}

\section{Les premières représentations vishnouites}

Cinq représentations vishnouites, au traitement plastique et à la construction particulièrement archaïques, nous paraissent devoir être considérées comme les plus anciennes créations de la statuaire de la basse vallée du Mékong ${ }^{11}$. Ces cinq œuvres proviennent de régions différentes du Cambodge, assez éloignées les unes des autres : Ta Keo, Stung Treng et Kandal ${ }^{12}$. Il s'agit des Viṣnu de Kompong Cham Kau, de Tuol Chhuk, de Tuol Koh et de Ba Srê (fig.1-3), et du Viṣnu Kalkin de Kuk Trap ${ }^{13}$. À l'exception de cette dernière pièce, ces images sont plus précisément à mettre en relation avec la série des Viṣnu mitrés à vêtement long qui se retrouvent sur les divers autres sites d'Asie du Sud-Est.

Pierre Dupont considérait bien celles d'entre ces images qu'il connaissait comme les plus anciennes de la série des Viṣnu à vêtement long (le Viṣnu de Ba Srê est une découverte toute récente); il en situait la production au début du VIIc siècle, en les regroupant dans ce qu'il qualifiait de groupes secondaires du Zhenla ${ }^{14}$. Ces quatre statues ont de ce fait toujours été classées par la suite comme des pièces postérieures aux images du Phnom Da, dont la production était placée par P. Dupont au début du VI ${ }^{\mathrm{e}}$ siècle. Dans l'ensemble, les historiens de l'art se sont en effet accordés pour faire de ce style du Phnom Da, pourtant très abouti, la plus ancienne manifestation artistique du Cambodge ${ }^{15}$.

Or les caractéristiques de ces cinq pièces du Cambodge nous paraissent bien indiquer plutôt qu'elles seraient antérieures au style du Phnom Da. En effet, ces statues sont

11. Nadine Dalsheimer, Le corps des dieux : la plastique dans la statuaire khmère et ses relations avec celle des pays voisins. Thèse de III $^{\mathfrak{c}}$ cycle, université de Paris III, 1997, chap. 1 (« La formation d'un art »).

12. La province de Stung Treng est située à l'extrême Nord-Est du Cambodge actuel et donc loin des centres présumés de production des autres Viṣnu mitrés, situés dans le Sud du pays. La statue de Kompong Cham Kau qui en provient s'y trouve donc isolée. Henri Parmentier souligne qu'il existait une ancienne ville à cet emplacement (1927, vol. I, p. 230, 310 et fig.106).

13. a.- Visnu de Kompong Cham Kau (prov. de Stung Treng) (MNPP, n ${ }^{\circ}$ B.30.5 ; H : 1,95 m) ; b.- Viṣnu-Kalkín de Kuk Trap (prov. de Kandal) (MNPP : $\mathrm{n}^{\circ} \mathrm{B} .253$, grès ; H : 1,33 m) ; d'autres représentations d'une facture proche proviennent de la même province de Kandal : un Ganeśa assis (MNPP : $n^{\circ}$ B.251) et c.- Viṣnu de Tuol Chuk dont il est également question dans cette série (MNPP : $\mathrm{n}^{\circ} \mathrm{B} .30 .10$, grès, $\mathrm{H}: 0,95 \mathrm{~m}$ ) ; d.-Viṣnu de Tuol Koh (prov. de Ta Keo) (MNPP : $\mathrm{n}^{\circ} \mathrm{B} .302 .9$, grès, $\mathrm{H}$ : $0,95 \mathrm{~m}$ ); d'autres pièces, trouvées aussi dans la province de Ta Keo, peuvent être rattachées à un même atelier : le Krșna Govardhana de Vat Koh (Prei Krabas, Angkor Borei, MNPP : n 31,5, grès, H : 1,59 $\mathrm{m}$ ) ; le Skanda d'Angkor Borei (MG : $\mathrm{n}^{\circ} 126$, grès, $\mathrm{H}: 1,03 \mathrm{~m}$ ) ; une statue féminine trouvée au Phnom Da (MNPP : $\mathrm{n}^{\circ}$ B.71.2, grès, H : 0,40 m) ; e.- Viṣnu de Ba Srê (MNPP : donation de 1997 par le Premier ministre Hun Sen, non encore numéroté et mesuré).

14. Dupont $1941,1955: 123-124$.

15. Cœdès 1942, p. 155-156; Dupont 1941, 1955 ; Boisselier 1955, p. 22, 206, 227 ; Giteau 1965, p. 34-35 ; B.-P. Groslier 1995, p. 875-876 (sur le changement d'opinion de J. Boisselier sur ce point, voir infra, note 32). On supposait néanmoins l'existence d'une statuaire précédant celle du Phnom Da, mais en émettant l'hypothèse qu'elle était en bronze, en bois ou en terre cuite. $P$. Dupont situait cette production d'images pressenties à la fin du $\mathrm{v}^{\mathrm{c}}$ siècle et la rendait contemporaine des sculptures Gupta de Mathurā (Dupont 1955, p. 26, 33, 40, pages où se font jour ses nombreuses hésitations sur la transmission depuis des prototypes indiens encore mal connus à l'époque; à propos de cette production supposée disparue, voir aussi Boisselier 1955, p. 22 ; Giteau 1965, p. 34). 
encore largement liées au haut-relief : les Viṣnu de Tuol Koh et de Kompong Cham Kau sont sculptés plus sous forme de stèles que de véritables rondes-bosses animées dans l'espace. D'autres détails, tels le traitement plastique excessivement raide du corps, où la musculature est parfois figurée, le thorax penché en arrière (Viṣnu Kalkin de Kuk Trap et Viṣnu de Kompong Cham Kau), l'attitude frontale et la forme simplifiée des jambes sont également des éléments en faveur d'une datation plus haute.

Parmi les nombreuses pièces de la région de $\mathrm{Ta} K e o$, la statue de Viṣnu exceptionnellement plate trouvée sur le site de Tuol Koh avait déjà attiré l'attention de P. Dupont. Il la qualifiait «d'image isolée » au Cambodge, mais notait aussitôt des altérations de proportions comparables à celles présentes sur des pièces du delta du Mékong et de la péninsule Malaise (parmi lesquelles il cite le Viṣnu de Chaiya). Bien qu'il se soit demandé d'abord s'il pouvait s'agir «d'une production d'un archaïsme exceptionnel », il conclut qu'il ne pouvait attribuer une datation haute à ce Viṣnu de Tuol Koh car, écrivait-il, « un des axiomes de l'archéologie du Sud-Est asiatique est que les statues les plus proches de la tradition indienne dans ce qu'elle a de classique sont aussi les plus anciennes. C'est le cas notamment des statues du Phnom Da. L'archaïsme se traduit donc par la plus grande perfection des formes ». On voit bien là comment l'application quasi aveugle de cet «axiome », qui n'est aucunement appuyé par la présentation de prototypes indiens concrets, conduit P. Dupont, et conduira J. Boisselier à sa suite, à rejeter toute datation haute pour les pièces les plus archaïques de cette famille, esthétiquement si peu conformes à un «classique » indien idéalisé. Cela amena ainsi ces auteurs à laisser de côté cette série de pièces à vêtement long, regroupées par P. Dupont en un groupe secondaire, qualifié d'aberrant, et qui ne pouvait en tout état de cause précéder chronologiquement les pièces stylistiquement plus abouties de l'art du Phnom Da ${ }^{16}$.

Stanley O'Connor, par contre, place le Viṣnu de Tuol Koh, avec les plus anciennes pièces de la péninsule Malaise, dans la lignée immédiate des prototypes de Mathurā des $\mathrm{III}^{\mathrm{c}}$ et IVe siècles dont l'une des principales caractéristiques est d'avoir la conque basse, posée sur la hanche gauche. Parmi celles-ci, le Vișnu de Chaiya constitue, comme on l'a vu plus haut, la plus ancienne représentation de Viṣnu mitré et peut ainsi être daté de l'extrême fin du IV ${ }^{e}$ siècle, sur la base de comparaisons avec des prototypes Kușāna de Mathurā ${ }^{17}$. Nous ajouterons que la statue de Chaiya, comme celle de Tuol Koh, ne peut également manquer d'être comparée à celles, en haut-relief, des grottes Gupta d'Udayagiri datées par l'épigraphie du tout début du ve siècle ${ }^{18}$. On notera enfin que la disposition de l'écharpe torsadée sur la statue de Tuol Koh, placée en oblique sur les hanches, est un élément que l'on retrouve aussi sur les représentations indiennes de Mathurā et qui fait encore pencher la balance en faveur d'une date haute pour ce Viṣnu, vraisemblablement dans la première moitié du Ve siècle ${ }^{19}$. Il est donc bien proche ainsi des pièces contemporaines découvertes en péninsule Malaise ou à Java, et doit être rapproché aussi de celles recueillies près de Óc Eo, sur le territoire du Funan ${ }^{20}$. La

16. Dupont 1955 , p. 122-134.

17. S. O’Connor analyse cette pièce en détail (1972, chap. 2); voir aussi Boisselier 1959, p. $59-69$.

18. Voir en particulier le Vișnu sculpté en haut-relief de la porte d'entrée de la grotte 6 d'Udayagiri (Harle 1974, p. 33-34, pl. 8, et Harle 1986, p. 91, pl. 66).

19. S. O'Connor (1972, p. 26 et surtout p. 43, note 9) réfute clairement les arguments de P. Dupont (voir ses pl. 6 et 9 pour des exemples indiens d'écharpes torsadées).

20. Les Viṣnu du mont Ba Thê, avec leur conque sur la hanche gauche, sont ainsi à placer parmi les pièces les plus anciennes du delta du Mékong, comme l'avait bien pressenti Louis Malleret dans son Archéologie du delta du Mékong, qui les date de la première moitié du Vie siècle (1959-63, vol.I, p. 363, pl. 82-84). S. O'Connor a plus tard affiné l'analyse des ressemblances entre les premiers Viṣnu de Thaïlande et ceux du Funan (1972, p. 28-29). L'inventaire systématique (en cours pour le territoire 
plastique maladroite du Viṣnu de Tuol Koh en fait donc probablement la plus ancienne de ces cinq œuvres (mais son piètre état de conservation ne permet pas de pousser plus loin son analyse plastique).

L'esthétisme du Viṣnu de Kompong Cham Kau révèle sans doute aussi une influence précoce de la péninsule Malaise vers le Cambodge : il est à lier plus directement encore à une statue provenant de Vieng Sra. S. O'Connor date cette représentation de Vieng Sra du VI ${ }^{c}$ siècle et la place en fin de production «funanaise » du Phnom $\mathrm{Da}^{21}$. Cette image de Vișnu, cependant, est encore en partie sculptée en haut-relief (des réserves de pierre sont visibles en plusieurs endroits) et paraît encore très proche de modèles indiens où la véritable ronde-bosse est rarement pratiquée. À l'inverse, les statues khmères du Phnom Da sont de réelles rondes-bosses, construites en trois dimensions (quand bien même elles sont soutenues par des arcatures et étais divers). Nous proposons donc de considérer la production de Viṣnu mitrés dont font partie ceux de Kompong Cham Kau et de Vieng Sra comme antérieure encore à celle des statues vishnouites du Phnom Da.

Les deux autres pièces se rapportant à cette série des premières manifestations de l'art du Cambodge, le Viṣnu de Tuol Chhuk et le Viṣnu Kalkin de Kuk Trap, sont déjà différentes de celles présentées jusqu'ici. Ces deux représentations vishnouites sont sculptées avec l'idée plus forte de la ronde-bosse et annoncent ainsi plus clairement la production du Phnom Da. Le Viṣnu de Tuol Chhuk est très proche des statues trouvées à Vieng Sra, dont les traits du visage sont charnus et l'expression sereine, un peu froide. Le corps se distingue par une musculature puissante et naturaliste, des hanches droites et des cuisses bombées, caractéristiques fréquentes des sculptures indiennes de Mathurā. La mitre est oblique, le vêtement long est maintenu par une écharpe horizontale nouée autour des hanches et faisant un gros nœud bouffant sur le côté droit.

La silhouette du Visnu Kalkin de Kuk Trap surprend tant la partie supérieure du corps est raide et penchée vers l'arrière. Le raccord avec la tête est particulièrement bien réussi, ce qui témoigne de la complète maîtrise du sculpteur de l'époque; la comparaison avec les exemples de Varaha de l'époque Gupta est intéressante à ce titre ${ }^{22}$. La tête est d'une facture soignée aux yeux fortement ourlés et aux naseaux figurés en virgule. La partie supérieure du corps présente un torse puissant, solidement structuré. Les mamelons sont indiqués par des cercles concentriques et trois lignes rayonnantes encadrent le nombril. Le vêtement est maintenu par une écharpe plate aux motifs en larges stries qui suggèrent les plis de l'étoffe enroulée. Le pan de tissu tombant entre les deux jambes est incisé de décor en vagues simulant les courbes naturelles du vêtement. L'attitude déhanchée du corps, le torse raide et carré aux épaules inclinées vers l'arrière, les cuisses bombées, sont des formules plastiques à mettre en relation avec les statues thaillandaises de Si T'ep ${ }^{23}$. Le galbe des cuisses ainsi que la ceinture se terminant par un nœud bouffant sur le côté droit rappellent des représentations indiennes de Mathurā, telles que le Nagarāja du musée Guimet ${ }^{24}$. Ce roi-serpent, debout, au corps fortement hanché à gauche, possède une silhouette souple : une ligne serpentine traverse le corps, rejetant le thorax et les épaules en arrière. Ce mouvement du thorax se retrouve précisément sur le Viṣnu Kalkin de Kuk Trap, mais

vietnamien dans le cadre de la Mission archéologie du delta du Mékong) a livré près de cinquante pièces appartenant à différentes séries de cette même famille stylistique mitrée (dont plus de trente Viṣnu, onze Devī / Durgā et quatre Sūrya). Mais leur étude systématique est encore à entreprendre.

21. O'Connor 1972 : p. 42-49, pl. 15.

22. Voir notamment le Viṣnu Varaha provenant d'Eran (Madhya Pradesh) conservé au musée universitaire de Sagar et publié par Harle 1986, p. 99, pl. 75.

23. Boisselier 1974. Dans cet ouvrage, J. Boisselier présente l'école de Si T'ep et montre deux beaux exemples de ses représentations (p. 104-106 et pl. 69, 70).

24. Voir la représentation en grès rose du Nagarajā de Mathurā publiée par J.C. Harle (1986, p. $60, \mathrm{pl} .40)$; il est daté du $\mathrm{II}^{\mathrm{e}}-\mathrm{III}^{\mathrm{e}}$ siècle. 
avec plus de raideur. Le traitement du torse est aussi plus naturaliste sur le Nagarāja de Mathurā, mais le dessin des hanches et des cuisses est identique, au contour clairement délimité et au relief fortement convexe. Le Viṣnu Kalkin de Kuk Trap s'inscrit donc bien dans la lignée plastique de cette image de Mathurā .

Les caractéristiques qui témoignent de l'évolution ultérieure des formes peuvent de même être cernées avec exactitude. Le vêtement, par exemple, va se modifier progressivement : il est possible de suivre l'apparition des plis concentriques et le raccourcissement progressif du bord inférieur de la jupe ${ }^{25}$ (fig. 4). On y remarque aussi, comme sur les tempes du Viṣnu de Vat Pan Moral, la naissance discrète de boucles en anglaises. De même, les formes plastiques deviennent-elles de plus en plus souples et bien saisies (les bras multiples s'intègrent ainsi harmonieusement au corps). Le Viṣnu de Tuol Ang Kombot Ka (dit aussi de Chong Pisei, dans la province de Kandal ; fig. 5) est une œuvre ambiguë, caractéristique des transformations des formes des premiers Viṣnu : elle possède des caractères plastiques de la série la plus ancienne (petite taille, caractéristiques similaires dans les traits du visage) et, dans un même temps, des analogies avec les statues du Phnom Da (proportions harmonieuses du corps, apparition des boucles en anglaises sur la nuque, vêtement court à plissé rayonnant, avec une première apparition de la chute en ancre du vêtement) ${ }^{26}$.

\section{Les premières images khmères : problèmes de chronologie}

Dans cette perspective nouvelle, le style du Phnom Da, dont il est encore d'usage de faire la plus ancienne manifestation artistique du Cambodge, perd la place éminente qui lui était jusqu'ici accordée (sauf dans les derniers travaux de J. Boisselier, comme on le verra plus loin). La statuaire du Phnom $\mathrm{Da}$ apparaît alors désormais comme l'aboutissement d'un processus de formation artistique long déjà de plus d'un siècle, dans lequel les apports venus de l'occident ont joué un rôle prépondérant. On apporte ainsi une réponse aux interrogations répétées des historiens de l'art concernant l'étonnante maîtrise technique des artistes du Phnom Da, difficilement explicable s'agissant d'un premier essai dans l'art si difficile de la statuaire de pierre.

Une restitution du mouvement suivi par les influences étrangères peut être tentée ici, afin de mieux comprendre la formation des premières statues vishnouites du Cambodge ancien. L'influence indienne de l'époque Kușāna à Mathurā, comme nous l'avons évoqué précédemment, atteste de l'ancienneté de certaines des images trouvées au Cambodge. Ces premières statues de pierre du Cambodge sont également à rapprocher des Viṣnu à jupe de l'époque Gupta d'Udayagiri, plus tardives, dont les reliefs des grottes sculptées sont certainement les prototypes; elles peuvent ainsi être liées assez directement à la tradition indienne des hauts-reliefs de grottes excavées, dont on peut penser que des dessins ou des poncifs ont voyagé vers l'est. S. O'Connor a pu identifier l'Andhra Pradesh comme une étape côtière entre le Nord-Ouest de l'Inde et la traversée du golfe du Bengale. Il faut donc noter, à la suite des historiens de l'art qui se sont déjà penchés sur la question des relations des premières productions artistiques indianisées d'Asie du Sud-Est avec leurs prototypes indiens, l'impossibilité que l'on a d'identifier des références univoques à des modèles indiens, par trop hétérogènes. Mireille Bénisti

25. Quatre statues de Vișu montrent bien, entre autres, les étapes successives du raccourcissement du vêtement : Vat Pan Moral (MNPP, ${ }^{\circ}$ B.392; Boisselier 1955, pl. 20A); Tuol Ta Hoi (MNPP, n B.30.2, Boisselier 1955, pl. 21A); Tuol Komnap (MNPP, n 5760) (notre fig. 4) ; Srah Prah That (MNPP, $\mathrm{n}^{\circ}$ B.30.26 ; Dupont 1955, pl. XXII et Boisselier 1955, pl. $20 \mathrm{~B}$ ).

26. MNPP, n B.30.17; Dupont 1955, pl. IX. J. Boisselier (1966, p. 238) la classait à la suite de Dupont dans le style B du Phnom Da. 
constate que « si de nombreuses liaisons existent, certaines formant même des faisceaux privilégiés, ne se constate aucune transmission d'un ensemble cohérent de l'Inde en pays khmer ${ }^{27}$. Plus récemment, Bruno Dagens résume admirablement la question dans une brève notice intitulée «Le voyage en Orient, ou à chacun sa beauté » ${ }^{28}$. À ces remarques, il faut ajouter que ces formes indiennes sont d'abord adoptées et adaptées par les élites politiques et économiques d'une multitude de petits États cosmopolites nouvellement indianisés, dans une Asie du Sud-Est dont les structures politiques sont encore largement polycentriques, quoi que paraissent en dire les sources chinoises contemporaines. Dans ces circonstances, comment peut-on imaginer que l'on pourrait recueillir aujourd'hui les témoignages d'une évolution simplement linéaire des formes artistiques? Des chevauchements se sont inévitablement produits, d'une période à l'autre, d'une région à l'autre.

De plus, lorsqu'on considère les formes artistiques qui voient le jour en péninsule Indochinoise, il apparaît aussi qu'une part importante de ces apports indiens a transité par la péninsule Malaise. En effet, les analogies plastiques entre les pièces du Cambodge et celles provenant de l'actuelle Thaïlande péninsulaire (et, plus au nord, celles de Si T'ep) sont indéniables et attestent des liens géographiques et historiques étroits que devaient entretenir ces deux régions. Les États anciens de l'isthme de la péninsule Malaise, entre golfe du Bengale et mer de Chine méridionale, auraient ainsi servi de relais à la pénétration des influences indiennes vers le Cambodge, au cours du $V^{c}$ siècle et peut-être même dès la fin du IVe siècle. Comme l'avait déjà souligné H.G. Quaritch Wales dès les années 1930, il était logique de voir s'implanter des centres de diffusion de la culture indienne sur les sites de la péninsule Malaise (cet aspect particulier de l'histoire de la frange maritime de l'Asie du Sud-Est occidentale sera élaboré en conclusion de cet article) ${ }^{29}$. Cette première étape péninsulaire semble bien avoir déjà modifié l'esthétisme des formes voyageuses indiennes, comme l'attestent les pièces trouvées à Chaiya ou à Vieng Sra.

Les statues étudiées ci-dessus livrent donc des indications sur la formation de l'art khmer et sur la contribution cruciale des arts de la péninsule Malaise. Ces œuvres étaient considérées jusqu'à présent comme marginales ou aberrantes dans le schéma descriptif des sculptures des débuts de l'art khmer. Elles se comprennent mieux lorsqu'elles sont reliées aux pièces indiennes et thaïlandaises, fût-ce de façon globale : les particularités de leur traitement plastique leur assurent de fait - dans cette perspective nouvelle - le statut de plus anciennes représentations brahmaniques du Cambodge.

Le style du Phnom Da constitue en tout état de cause une production remarquable dans l'histoire de l'art de la région. On a vu comment il avait toujours servi de référence pour les historiens de l'art. Son rattachement à une période précise de l'histoire du Funan ou du Cambodge apparaît donc comme essentielle ; cette date est pourtant loin d'être établie, comme l'atteste le flou entretenu dans les études disponibles jusqu'à ce jour.

Pierre Dupont, le premier, l'attribue au roi Rudravarman, dont on sait par l'épigraphie qu'il a régné dans cette région vers 514-après 536 . Il se fonde sur le fait que des statues du panthéon vishnouite sont citées dans une inscription trouvée au Phnom Da, paléographiquement datée du XIIc ou même du XIIIc siècle, et qui fait peut-être référence à ce roi Rudravarman. Le panthéon nommé dans cette inscription paraît bien en effet correspondre à celui, tout à fait exceptionnel, qui a été retrouvé au Phnom Da : une

27. Bénisti 1970, p. 99-101.

28. Dagens 1993.

29. Wales 1961, p. 54-55. Les travaux de H.G. Quaritch Wales sont cités par S. O'Connor 1972, p. 20. 
partie des statues de ce site a d'ailleurs été retrouvée dans un sanctuaire lui-même tardif, où elles faisaient donc toujours l'objet d'un culte, ce qui peut suffire à expliquer leur mention dans cette inscription tardive. Mais G. Cœdès lui-même écrivait, lorsqu'il la publia, qu'il était convaincu « de la difficulté de tirer de ce document autre chose que des mots sans suite, et de l'impossibilité d'en donner une traduction cohérente », en raison en particulier de « la grande irrégularité de caractères très négligemment tracés ${ }^{30}$. Cette épigraphe ne peut fournir à elle seule un argument définitif en faveur d'une datation haute du Phnom $\mathrm{Da}$ : son attribution à un roi hypothétique ayant régné quelque six siècles plus tôt nous semble bien peu fiable dans ce contexte, et en tout état de cause insuffisamment établie, s'agissant d'un style considéré comme aussi crucial. B. P. Groslier, dans des ouvrages de synthèse et sans plus d'argumentation, a suivi P. Dupont dans cette voie. Madeleine Giteau est moins affirmative lorsqu'elle écrit que les statues du Phnom $\mathrm{Da}$ « ne sauraient être antérieures au VIe siècle », mais n'approfondit pas plus la question ${ }^{31}$. Jean Boisselier, après avoir longtemps suivi $P$. Dupont, penchait dans ses dernières brèves synthèses sur l'art khmer pour une datation rajeunie de près de deux siècles, vers la fin du VII ${ }^{c}$ ou même le début du VIII siècle ; mais il n'y fournissait pas d'arguments en faveur de cette nouvelle interprétation, s'agissant d'ouvrages destinés au grand public. Il affirme donc désormais « [qu']on ne connaît aucun édifice ou sculpture antérieurs au début du VII ${ }^{\mathrm{e}}$ siècle » à la fondation de Sambor Prei Kuk, pendant le premier quart du VII e siècle. Le style du Phnom Da se trouve donc rejeté par J. Boisselier à une période mal définie, mais postérieure semble-til à celui de Sambor Prei Kuk ${ }^{32}$.

La perspective nouvelle proposée ici ne permet pas de mieux dater ce style (ce n'est d'ailleurs pas là le but de cet article). Elle affirme par contre sans ambiguîté que l'on ne peut lui conserver son rôle pionnier, puisque des formes artistiques antérieures ont été identifiées. En l'état actuel des connaissances, la valeur de terminus ante quem pour la production des Vișnu mitrés à robe longue étudiés ci-dessus - tout particulièrement pour ceux d'entre eux trouvés en péninsule Indochinoise - doit donc être dévolue faute de mieux au style de Sambor Prei Kuk, quant à lui solidement rattaché par l'épigraphie aux règnes d'Iśānavarman et de son prédecesseur, pendant le premier quart du VII siècle ${ }^{33}$. Les Viṣnu mitrés à robe longue du Cambodge ne peuvent donc être postérieurs à la fin du VI' siècle.

30. Dupont 1941 et 1955 , p. $23-24$. L'inscription a été publiée dans le volume II des Inscriptions du Cambodge de G. Cœdès (1942, p. 155-156). Dupont note cependant encore qu'un deuxième souverain du nom de Rudravarman, du VIII' siècle mais moins célèbre celui-là, a de même régné dans la région.

31. Groslier 1995, p. 876-877; Giteau 1965, p. 34,35.

32. Voir la notice « Histoire de l'art khmer » de l'Encyclopaedia Universalis (édition CD-ROM $3.0,1997$, p. 13-321c, d'où nous avons tiré cette citation). Voir aussi la traduction anglaise de ses Tendances de l'art khmer, revue et mise à jour par l'auteur lui-même en 1986 et l'ouvrage sur l'art de l'Asie du Sud-Est publié en Italie en 1986 ; dans ce dernier travail, il datait le style du Phnom Da de la fin du VII ${ }^{c}$ ou au VIII ${ }^{c}$ siecles et le plaçait «très en marge de l'ensemble de la production »; c'est le style de Sambor Prei Kuk qui fournit désormais les images les plus anciennes de l'art « préangkorien » (Boisselier $1986 ; 1989$, p. 27-28). En fait, J. Boisselier exprimait déjà des doutes dès son étude majeure sur la statuaire khmère $(1955$, p. 22, 206) : « cette impression nous amènerait à penser volontiers que la statuaire est un fait plus ancien au Cambodge que ne l'indiqueraient les pièces actuellement retrouvées ». Dans la présentation la plus récente de cet art, à l'occasion de la grande exposition d'art khmer tenue en 1997, T. Zéphyr signale le changement de perspective de J. Boisselier dans ses dernières œuvres et hésite à trancher la question difficile de la date du style du Phnom Da; il s'en tient prudemment à la mention «VI ${ }^{\mathrm{e}}$ (?) - VII ${ }^{\mathrm{e}}$ siècles environ » (Jessup \& Zéphyr 1997, p. 143-145 et note 5).

33. Cœdès 1964 , p. 131-133. 
Il faut noter ici aussi qu'en datant du Ve et du VIe siècles les plus anciens d'entre ces Viṣnu mitrés à robe longue de la péninsule Indochinoise, on en fait indéniablement des productions artistiques émanant de l'État qu'il est convenu d'appeler le Funan, pendant ses deux derniers siècles d'existence ${ }^{34}$. Ce faisant, on rétablit pour la production artistique de la péninsule Indochinoise un équilibre chronologique qui, nous semble-t-il, lui faisait cruellement défaut. Géographiquement, le grand nombre de ces pièces trouvées de part et d'autre de la frontière moderne séparant le Cambodge du Viêt Nam fait par ailleurs pencher la balance en faveur d'un centre de gravité plutôt méridional pour leur production ou leur utilisation au Funan ${ }^{35}$.

\section{Le site archéologique de Kota Kapur}

Deux campagnes archéologiques ont été effectuées en 1994 et 1996 sur le site de Kota Kapur, dans l'île de Bangka (province de Sumatra-Sud, Indonésie), dans le cadre du Programme de recherches sur Sriwijaya, mené en coopération par le Centre national de la Recherche archéologique d'Indonésie et l'EFEO ${ }^{36}$.

L'objectif originel de ces campagnes était de comprendre pourquoi fut érigée une inscription en vieux malais, datée de 686 , en ce lieu périphérique par rapport au centre de l'Etat de Sriwijaya (situé à Palembang, en amont du fleuve Musi) ${ }^{37}$. On rappelera ici que le toponyme Bangka, qui désigne l'île sur laquelle est situé le site de Kota Kapur, doit vraisemblablement être reconnu sous la forme Warika, qui apparaît déjà dans le Mahāniddesa, ouvrage bouddhique en langue pāli dont la rédaction est située vers la fin du III'c siècle ${ }^{38}$. L'île, à défaut du site lui-même de Kota Kapur, paraît donc bien avoir été connue très tôt des auteurs indiens.

Les résultats des campagnes archéologiques furent inespérés. Les fouilles révélèrent rapidement une structure en pierre à l'architecture assez sommaire, puisqu'il s'agit d'une simple terrasse carrée de 5,60 m de côté, haute seulement de quelque $0,60 \mathrm{~m}$, à laquelle on accédait par un petit escalier situé sur la face nord (fig. 6) ${ }^{39}$. Au cours du dégagement de ce monument, de nombreux fragments de statues furent mis au jour: une fois rassemblés, on a pu reconstituer partiellement quatre pièces appartenant toutes, sans doute aucun, à la famille des statues mitrées décrite plus haut. À ces quatre pièces, on doit ajouter la représentation masculine à quatre bras publiée par Stutterheim en 1937. La structure mise au jour constituait donc le sanctuaire qui abritait ces images. On

34. G. Cœdès, dans ses États hindouisés d'Indochine et d'Indonésie (1964, p. 120), en se fondant sur la chronologie alors admise, concluait que ces images, «sans appartenir à l'art du Fou-nan, donnent quelque idée de ce qu'a pu être sa statuaire ». Cette constante ambiguïté dans le propos constitue une autre illustration de la cote mal taillée que l'on faisait endosser à ces statues.

35. Voir supra note 20.

36. On trouvera une première présentation de ce site de Kota Kapur dans Koestoro, Manguin et Soeroso 1998.

37. Les premiers résultats de ces recherches sur Sriwijaya ont été sommairement présentés dans Manguin 1987, 1992 et 1993.

38. Codès 1964, p. 107 ; Damais 1959, p. 814.

39. Le mauvais état de conservation de cette structure n'a pas permis de déterminer avec certitude s'il s'agissait d'un monument à un seul étage (une terrasse portant vraisemblablement une structure en bois), ou bien si les étages ultérieurs n'avaient pas été conservés. Tout porte à croire cependant que la première solution est la plus probable (Koestoro, Manguin et Soeroso 1998 ; la campagne de 1994 est seule publiée dans cet article ; les datations par le ${ }^{14} \mathrm{C}$ et les résultats de la campagne de 1996 restent inédits). 
a là, à notre connaissance, le seul site connu en Asie du Sud-Est où l'association entre des Viṣnu mitrés et un temple bâti soit avérée.

Un deuxième sanctuaire, situé à $40 \mathrm{~m}$ environ au nord-ouest du premier, est plus petit de moitié. Il est constitué d'une simple terrasse de $2,80 \mathrm{~m}$ de côté et porte encore en son centre un linga, sous la forme d'une pierre naturelle dressée, peut-être légèrement travaillée pour accentuer son aspect phallique.

Sous les fondations de ce deuxième sanctuaire, on a aussi commencé de fouiller un atelier de travail du fer, qui lui est donc antérieur : trois datations par le radiocarbone d'échantillons de charbon recueillis dans cette couche épaisse sont cohérentes mais donnent une fourchette chronologique trop large pour permettre de fournir une date précise. Tout au plus peut-on dire en l'état actuel des résultats que les temples ne peuvent être antérieurs à 532, terminus a quo pour la plus récente des trois datations ${ }^{40}$.

Des sondages ont par ailleurs été effectués à Kota Kapur sur plusieurs sites d'habitat ripuaire, riches en céramique. Un rempart de terre de $2,5 \mathrm{~km}$ de côté, haut par endroits encore de $4 \mathrm{~m}$, a enfin été identifié et relevé topographiquement ; il pourrait être contemporain de ces sanctuaires ${ }^{41}$.

\section{La statuaire de Kota Kapur ${ }^{42}$}

Une petite pièce très incomplète, trouvée dès la fouille des carrés d'essai préliminaires à la campagne 1994, provient du temple vishnouite de Kota Kapur. Ce fragment $\mathrm{n}^{\circ} 1$ est haut de $16 \mathrm{~cm}$, cassé sous les pectoraux et au-dessus des genoux, et appartient probablement à une représentation masculine (fig. 7) (on se reportera à l'analyse plastique plus complète des pièces de Kota Kapur, infra, en appendice). Le corps, au modelé souple, présente un léger déhanché à droite. Une réserve de pierre sur la hanche gauche indique qu'une main devait y être rattachée, comme c'est alors fréquemment le cas. La jupe est lisse sans indication de décor incisé. Les distinctions plastiques situent ce fragment à une date proche de celle du Viṣnu $\mathbf{n}^{\circ} 2$ de Kota Kapur.

La statue $n^{\circ} 2$ de Kota Kapur, incomplète, a été trouvée en plusieurs morceaux pendant les fouilles de 1994 et de 1996 (le buste fait environ $17 \mathrm{~cm}$ de haut, sans les bras ; fig. 8-9). Ce corps trapu est distinctif de la famille stylistique des Viṣnu mitrés et ses caractéristiques plastiques, techniques et iconographiques placent d'emblée cette représentation avant la production artistique du Phnom $\mathrm{Da}$, comme cela était le cas pour l'exemple précédent. Le visage annonce déjà celui des statues du Phnom $\mathrm{Da}$, avec un contour large et ovale, des arcades sourcilières courbes et hautes, des paupières gonflées au traitement précis et des joues pleines et charnues. Cependant, des nuances distinguent nettement le visage de Kota Kapur $n^{\circ} 2$ de ceux de la production du Phnom $\mathrm{Da}$ : les yeux sont plus petits et taillés en amande, alors qu'ils seront plus sinueux sur la majorité des statues du Phnom Da ; le nez est fin, droit alors qu'il sera légèrement busqué au Phnom $\mathrm{Da}$; les lèvres sont plus droites, étirées, et le pli sous-mentonnier

40. Les couches attestant de ce travail du fer viennent s'insérer clairement sous les fondations en gravier de latérite du petit sanctuaire. Trois datations par le ${ }^{14} \mathrm{C}$ sur le charbon présent dans cette couche donnent les dates suivantes, après calibration (2 sigma) : 220-590 après J. - C. (1670 $\pm 80 \mathrm{BP}$; Batan, Yogyakarta), 428-538 (1590 \pm 20 BP ; Gif-10667), 532-680 (1450 \pm 50 BP ; Gif-10668). Le fer produit localement alimentait encore les exportations de l'île à l'arrivée des Hollandais au XVII' siècle.

41. Après la fouille de ce rempart en 1994, une datation par le ${ }^{14} \mathrm{C}$ des brûlis qui ont précédé sa construction donne une date calibrée qui va de 460 à 870 apr. J.-C. (1390 280 BP ; Gif 10231).

42. À l'exception du socle à tenon de Durgā Mahișāsuramardinī, conservé au Museum Balaputradewa de Palembang, les autres pièces appartiennent aux collections du Centre national de la Recherche archéologique d'Indonésie (et sont actuellement conservées au Balai Arkeologi de Palembang). 
n'est pas présent. Par ailleurs, la représentation $n^{\circ} 2$ de Kota Kapur reste proche encore de pièces indiennes telles que celle de Mandasor, datée environ de $500{ }^{43}$.

Le Viṣnu $n^{\circ} 3$, la plus grande et la plus complète des quatre représentations provenant du site de Kota Kapur, représente le dieu debout, à quatre bras (elle fait environ $80 \mathrm{~cm}$ de haut sans son socle ; fig.10-11). Les caractéristiques principales de cette statue sont la mitre haute et cylindrique, l'arc de soutien transverse, la plastique souple et soignée, le visage ovale aux yeux étirés, la chevelure constituée de boucles en anglaises et l'étoffe plissée du vêtement. Cette représentation de Kota Kapur, comme les statues de la péninsule Indochinoise dont elle est proche, appartient bien à ce type de représentations uniquement vishnouites qui annonce très directement, comme on l'a déjà dit, la plastique des statues du Phnom Da. Comme ces dernières, le Vișṇu ${ }^{\circ} 3$ de Kota Kapur se distingue notamment par l'aptitude du corps à investir l'espace dynamiquement. Cette capacité des statues du Phnom Da à montrer une représentation dans son ensemble n'est pas une constante de la ronde-bosse khmère, qui privilégie volontiers la statue vue de face. Cette façon remarquable de sculpter fait allusion à une tradition extérieure, peut-être venue de Perse. Plusieurs auteurs ont évoqué à ce propos les rapports entre la statuaire du Funan et les canons iconographiques de l'Inde septentrionale, constitués sous l'influence des Scythes et du monde iranien, et qui intègrent déjà nombre de ces traits exotiques ${ }^{44}$. Ceci expliquerait, par ailleurs, la coiffure à boucles en anglaises qui apparaît sur la nuque des pièces de Kota Kapur et qui sera une constante aussi de l'art du Phnom $\mathrm{Da}^{45}$. Les plis concentriques apparaissent ici sur le vêtement long.

La quatrième représentation masculine à quatre bras de Kota Kapur est conservée depuis les années 1930 au musée national de Jakarta (fig.12). Les qualités de représentation de cette statue sont à mettre en relation avec la production de Sūrya trouvée dans le delta du Mékong : une sculpture de Sūrya provenant de Tiên Thuân est ainsi directement à relier par sa plastique à celle de Kota Kapur (fig. 13) ${ }^{46}$. Les caractéristiques du Sūrya de Tiên Thuân semblent en faire une statue contemporaine de celles des représentations du Phnom Da avec lesquelles les affinités sont marquées : cadre large et ovale du visage, front dégagé, arcades sourcilières courbes, en léger relief, joues rondes sans rendu des pommettes, bouche courte aux lèvres apparemment fines et sensiblement relevées aux commissures, menton court et bien structuré, cou cylindrique, épaules larges et carrées, pectoraux bombés. Par ailleurs, d'autres détails tels que la mitre large et basse, la frange et les boucles cylindriques placées sur les tempes renforcent ce rapprochement. Si la plastique des autres Sūrya est clairement postérieure à celle des statues du Phnom $\mathrm{Da}$, celle de Tiên Thuân paraît en être contemporaine tant les affinités sont directes. Il est donc possible de proposer pour la représentation de Kota Kapur $n^{\circ} 4$ du Musée national de Jakarta une date proche ou identique de celles de Tiên Thuân et du Phnom Da. Cette statue pourrait donc être légèrement postérieure aux précédentes.

Une dernière pièce, très fragmentaire, provient également du temple vishnouite de Kota Kapur. Cette pièce $n^{\circ} 5$ est un socle à tenon, large de $17 \mathrm{~cm}$, sur lequel reposent

43. Voir Williams 1980, pl. 218.

44. Sur les rapports nombreux avec l'art indo-scythe via l'Inde du Nord-Ouest, on consultera en particulier Kamaleswar Bhattacharya (1961, p. 128-131), l'étude de V. Goloubew sur les images de Sūrya au Cambodge (1940), Codès 1964, p. 91-94 et O'Connor 1972, p. 36.

45. Certains objets venus du monde iranien pourraient attester de contacts directs : ainsi un cabochon de verre en pâte bleu turquoise découvert à Óc Eo. Ce cabochon porte une effigie parthe où est figuré un personnage aux longues boucles cylindriques similaires à celles de nos statues. Il est illustré dans L. Malleret (1959-63, tome III, p. 294, 304 et pl. 1, XXIII). Des reliefs rupestres d'Iran figurent toujours au III' siècle ces longues boucles cylindriques en anglaises (Porada 1963, p. 200).

46. Dupont 1955, pl. XIV A. 
encore les seuls pieds de la statue qui y était dressée. Sur les côtés des pieds sont visibles, à droite, la trace d'arrachement d'un étai de soutien et à gauche une réserve de pierre, probablement la base d'une massue, par analogie avec les autres statues contemporaines, plus complètes, trouvées dans l'ensemble de la région (fig. 14). Cette image portait donc vraisemblablement les attributs de Viṣnu. Sur sa face avant, cependant, ce socle est sculpté d'une tête de buffle, ce qui indique que la statue était une Durgā Mahișāsuramardanī. Cette déesse apparaît fréquemment dans la série des statues mitrées du delta du Mékong avec les attributs de Viṣnu : elle est, sous cette forme, l'une des représentations possibles de la déesse suprême Devì, et un culte lui était ainsi rendu par les adeptes du vishnouisme ${ }^{47}$.

Cette dernière pièce, quoique très incomplète, s'intègre donc bien au panthéon d'un sanctuaire vishnouite du Ve-VIe siècle, tel qu' on le trouve représenté dans la basse vallée du Mékong ou en péninsule Malaise. Elle contribue ainsi à faire de Kota Kapur un maillon essentiel du réseau tissé par ces sites en Asie du Sud-Est occidentale. Le petit temple secondaire dédié à Siva sous sa représentation phallique, révélé par les fouilles de Kota Kapur de 1996, ne dépare pas non plus dans ce contexte : dans toutes les régions où l'on a trouvé des statues de Viṣnu mitrés, accompagnées d'images beaucoup moins nombreuses de Sūrya et de Durgā, des linga, le plus souvent de petite taille, sont aussi présents. Pour compléter ce panthéon, seule manque donc à Kota Kapur une statue de Sürya.

\section{L'interprétation du site}

Les données sur le site de Kota Kapur présentées plus haut, combinées aux indications fournies par la statuaire, exceptionnellement trouvée dans son contexte archéologique, permettent d'en proposer une interprétation homogène. Certes, aucune des indications chronologiques - qu'elles proviennent d'études stylistiques ou du radiocarbone - ne peut donner une datation absolue qui permettrait d'asseoir ce raisonnement sur des certitudes. Mais notre interprétation a la vertu de concilier l'ensemble des données archéologiques disponibles, de les organiser dans une séquence chronologique cohérente, et de s'accorder en outre avec les modèles de formation des États de la région les mieux acceptés à ce jour.

Contrairement à ce qu'avait pu en penser Stutterheim, qui disposait en 1937 de bien peu d'éléments de comparaison et d'une seule petite statue mitrée, les deux sanctuaires, et par conséquent la statuaire qui leur est associée, ne peuvent pas avoir été érigés par l'État de Sriwijaya dans sa période de fondation, pendant le dernier quart du VII ${ }^{\mathrm{e}}$ siècle. On a vu plus haut que, en se fondant sur les éléments autres que la statuaire, les temples de Kota Kapur ne pouvaient être antérieurs à $532^{48}$. Le fait que la statuaire de Kota Kapur présente des caractéristiques stylistiques antérieures aux premières années du VII siècle réduit la fourchette chronologique pendant laquelle ces temples ont pu être fondés aux années 530-600. Une datation des environs de la deuxième moitié du VIc siècle nous paraît dans ces conditions constituer une approximation raisonnable.

47. On trouvera décrites de telles représentations de Devī / Durgā vainquant le démon-buffle en particulier dans le catalogue du musée Blanchard de la Brosse de Louis Malleret (1937, p. 74-75), ou dans son Archéologie du delta du Mékong (1959-63, vol. I, p. 443, fig. 66). Malleret les classe comme des représentations de Umā, parèdre de Siva. Sur la place de Durgā dans les rituels vishnouites indiens, voir Rao 1914-16, Tome I, vol. 2, p. 327-346. Pour le Cambodge, on se reportera au travail de Kamaleswar Bhattacharya, qui voit pour sa part dans ces représentations un exemple de syncrétisme (1961, p. 91, 151). Sur l'apparition de Durgā vainquant le buffle, dans un contexte vishnouite, à Udayagiri, voir Williams 1982 , p. 43.

48. Voir supra note 40. 
Tout laisse donc à penser que ce site de Kota Kapur a connu pendant cette deuxième moitié du VIe siècle des développements locaux, avec formation de structures politiques plus élaborées, qui ont fait appel comme ailleurs en Asie du Sud-Est à des pratiques rituelles d'origine indienne, en l'occurence un culte vishnouite (qu'il serait normal de voir associer au pouvoir politique). Ce pouvoir instauré à Kota Kapur constituait probablement l'un de ces multiples petits systèmes politiques installés alors sur les deux côtes du détroit de Melaka et dont le principal revenu était le commerce maritime (comme l'attestent entre autres les sources chinoises) ${ }^{49}$.

Le site de Kota Kapur permettait certes de contrôler le trafic maritime du détroit de Bangka, passage obligé entre, à son nord, les détroits de Melaka (menant vers l'océan Indien) et de Singapour (vers la mer de Chine) et, à son sud, la mer de Java avec, audelà, le Grand-Est indonésien et ses épices et bois précieux. Mais un tel contrôle ne justifie pas à lui seul l'essor d'un État, si modeste soit-il. Les productions de Bangka, qui sont attestées à partir du XVIIe siècle dans les sources écrites, sont le fer, l'étain et le poivre ${ }^{50}$. Cependant, les recherches archéologiques menées récemment n'ont pas encore permis de confirmer l'exploitation des deux dernières ressources - minerai stannifère et poivre - à haute époque. Peut-être est-on aussi en droit d'émettre l'hypothèse que le pouvoir installé à Kota Kapur contrôlait déjà les productions nombreuses du bassin fluvial de la Musi, sur l'île voisine de Sumatra, dont le delta débouche justement sur la rive opposée du détroit de Bangka ? L'or et les produits forestiers de l'intérieur de la grande île contribueront à la fortune de Sriwijaya à partir du dernier quart du VII e siècle. Lorsque ce nouvel État s'installe sur la Musi dans les années 670-680, son premier souci est précisément de centraliser à Palembang les activités économiques partagées jusque là entre de multiples centres politiques. Six inscriptions en vieux malais aux contenus pratiquement identiques sont ainsi produites dans les années 680 : autour de l'inscription «centrale », la plus élaborée, située à Palembang même, elles marquent l'un des cercles de l'expansion du pouvoir politique et économique nouvellement installé à Sumatra ${ }^{51}$. Le nouvel État professe le bouddhisme du Māhāyana, sous une forme tantrique dont l'épigraphie atteste l'orthodoxie ${ }^{52}$. Dans cette optique, l'inscription de Kota Kapur, qui fait partie de ce groupe de six, marque la prise de contrôle de l'ancien site vishnouite par Sriwijaya, le nouvel État fort de la région.

La durée d'utilisation de ces temples encore rudimentaires, qui semblent bien n'avoir connu en outre qu'une unique phase de construction, paraît donc s'arrêter à cette date : à notre connaissance, aucune fondation bouddhique ne vient alors remplacer ou compléter les sanctuaires brahmaniques; le site cesse ainsi de fonctionner en tant que centre politique. Ses activités économiques se poursuivent cependant, comme l'attestent la présence, très réduite il est vrai, de céramiques chinoises à partir du IX ${ }^{c}$ siècle.

49. On se reportera à l'étude fondamentale de Wolters sur l'histoire économique de l'Asie du Sud-Est insulaire, qui a jeté les bases de toutes les études historiques récentes sur le premier millénaire dans la région (Wolters 1967). Fondées alors pour l'essentiel sur les sources écrites (chinoises surtout), les hypothèses proposées par O.W. Wolters sont en grande partie confirmées par les recherches archéologiques récentes (pour une évaluation des progrès dans ce domaine, on lira en particulier Christie 1995).

50. Voir en particulier l'étude de M. F. Somers Heidhues (1992). (1993)

51. On trouvera l'interprétation la plus récente de ces inscriptions dans leur relecture par H. Kulke

52. G. Cœdès a traduit deux de ces inscriptions, dont celle de Kota Kapur $(1918,1930)$. La grande inscription centrale (dite de Telaga Batu, ou aujourd'hui, plus correctement, de Sebokingking) a été publiée par J. G. de Casparis (1956, p. 15-46). Les trois autres inscriptions périphériques portant le même texte ont été trouvées plus récemment et publiées en Indonésie. 


\section{La première statuaire vishnouite de l'île de Java}

\section{Les sites archéologiques de la baie de Jakarta}

On connaît depuis longtemps l'existence du groupe de cinq inscriptions sanskrites trouvées dans les environs de Jakarta et de Bogor, qui font état d'un souverain nommé Pūrnavarman, régnant sur le pays de Tārumānāgara. Datées paléographiquement du milieu du $V^{c}$ siècle, elles constituent avec celles de Kutei, à Bornéo, les plus anciennes inscriptions de l'Asie du Sud-Est insulaire ${ }^{53}$. C'est de cette même région côtière, et plus précisément du site de Cibuaya, que proviennent les trois Viṣnu mitrés décrits cidessous. Ces découvertes, longtemps coupées de tout contexte archéologique, étaient difficiles à interpréter ${ }^{54}$. Mais des nouvelles recherches menées depuis 1985 par divers archéologues indonésiens, bien que limitées, permettent aujourd'hui de nets progrès en la matière. Des fouilles systématiques devront cependant être menées sur ces sites pour que ces progrès soient entièrement confirmés ${ }^{55}$.

Bien plus qu'à Kota Kapur, les avancées récentes de l'interprétation archéologique de ces sites très riches privilégient la longue durée. La réintégration dans une séquence chronologique longue de données jusqu'ici dispersées accorde ainsi à la baie de Jakarta une place essentielle dans l'histoire des réseaux d'échanges maritimes de la région. Les céramiques roulettées qui y furent trouvées dans les années 1960 à Buni, en association avec des perles de verre et d'agate, attestent ainsi de ses relations économiques avec la façade orientale de l'Inde dès les tout derniers siècles av. J.-C. ${ }^{56}$. La production d'épigraphes écrits en sanskrit au $V^{c}$ siècle n'apparâ̂t plus ainsi que comme une nouvelle étape, marquée entre autres par l'adoption de pratiques rituelles indiennes, dans la formation des États de la région. Ces inscriptions, avec leur références à Viṣnu et aux brahmanes (l'une d'entre elles est aussi illustrée d'un symbole shivaïte), attestent des cultes brahmaniques (fig. 17). Dans les environs de Cibuaya même, un petit linga et les restes très endommagés de six structures en brique ont été récemment découverts, sans cependant que l'on puisse affirmer aujourd'hui que les statues de Viṣnu provenaient précisément de ces sites monumentaux (ces plateformes de plan carré, de $3 \mathrm{~m}$ à $10 \mathrm{~m}$ de côté, ne sont évidemment pas sans rappeler les deux monuments de Kota Kapur, associés sans ambiguité à leur statuaire).

\section{Les Viṣnu de Cibuaya}

La plastique du Viṣnu $n^{\circ} 1$ de Cibuaya (fig. 15) présente des analogies déjà remarquées par S. O'Connor avec le Viṣnu de Chaiya ${ }^{57}$. Le traitement en plaque sculptée de cette statue rappelle tout autant les premiers exemples de représentations de

53. Vogel 1925, p. 15-35 ; Casparis 1986, p. 242-256.

54. Dans son mémoire de maîtrise de 1963, Edi Sedyawati posait déjà la question du rapport entre les deux premières statues de Cibuaya et les inscriptions ; mais sa datation tardive de ces pièces, à la suite de Boisselier, lui fit rejeter toute corrélation directe.

55. L'essentiel de ces recherches n'est encore connu que sous forme de rapports non publiés et de communications à des colloques indonésiens. Ces travaux sont résumés, avec une bibliographie complète de cette « littérature grise » dans McKinnon, Hasan Djafar et Soeroso 1998.

56. Walker et Santoso Sughondo (1977). La découverte récente d'un nouveau site à céramique indienne roulettée sur la côte nord de Bali, donc plus à l'est encore, conforte l'interprétation des données de la baie de Jakarta (voir Ardika 1998, Ardika et Bellwood 1991).

57. Voir supra note 7 pour les références aux études sur cette statue de Cibuaya. 
Viṣnu dans le delta du Mékong décrites plus haut (la plus proche en est celle de Tuol $\mathrm{Koh}$ ). Comme on l'a vu, les statues mitrées du bassin du Mékong les plus anciennes peuvent être datées entre le milieu du $V^{c}$ et le début du $V^{c}{ }^{c}$ siècle; les analogies plastiques immédiates entre ces dernières et le Vișnu $n^{\circ} 1$ de Cibuaya sont des éléments en faveur d'une proximité chronologique. Ceci confère à la pièce de Cibuaya, dont la conque n'est plus portée sur la hanche, une date de la deuxième moitié du $\mathrm{V}^{\mathrm{c}} \mathrm{ou}$, au plus tard, du début du VIe siècle.

Le modelé général du corps et les éléments de parure, la coiffure et les vêtements du Viṣnu de Cibuaya $n^{\circ} 2$ - image sculptée sur fond de stèle - sont déjà très différents de ceux de l'exemple précédent (fig. 16). La plastique, moins archaïque, manifeste une meilleure maîtrise : le thorax présente le bombé naturel des pectoraux et la région abdominale traduit la vérité des chairs avec plus de souplesse. Par ailleurs, le vêtement est déjà incisé de plis concentriques. Si la datation proposée pour le Viṣnu $n^{\circ} 1$ de Cibuaya est la deuxième moitié du $V^{e}$ siècle, la statue $n^{\circ} 2$ serait ainsi de la fin du $V^{c}$ ou du début du VIc siècle.

La troisième statue trouvée à Cibuaya, de petite taille, très fragmentaire, et dont nous $n$ 'avons pu nous procurer une bonne illustration, ne permet pas une analyse fine. Tout au plus peut-on dire qu'il s'agit d'un autre Viṣnu de la même famille ${ }^{58}$.

Les trois images trouvées à Cibuaya en 1952, 1957 et 1975 sont taillées dans un même schiste de couleur noire, inconnu dans la région, mais attesté en Inde ${ }^{59}$.

\section{Les autres statues javanaises}

Deux autres statues en provenance de Java pourraient bien appartenir à la même famille que les images décrites plus haut et leur être à peu près contemporaines. Des indications peu précises de provenance pour la première, qui est de plus à la fois incomplète et assez atypique, et l'absence d'illustration pour la seconde nous interdisent cependant d'être aujourd'hui trop catégoriques en la matière. Il nous a cependant paru utile de les présenter ici, fût-ce de façon provisoire, pour tirer de l'oubli ces deux pièces qui, en tout état de cause, ne nous paraissent pas appartenir à l'art «classique » de Java central, postérieur au VII ${ }^{\mathrm{e}}$ siècle.

De plus, l'absence jusqu'ici de sites pré-classiques sur la côte nord de Java central et oriental nous paraît en toute logique être anormale, eu égard à l'existence de sites du début du premier millénaire à la fois à l'ouest de l'île et, à son orient, sur la côte nord de Bali. On doit d'ailleurs mettre en rapport les deux trouvailles qui suivent (et bien sûr aussi celles de l'Ouest de Java citées plus haut) avec la découverte — restée tout aussi confidentielle - d'un cachet en or d'inspiration indienne ou hellénistique acquis en 1916 à Pekalongan, sur la côte septentrionale de Java central ${ }^{60}$.

La première de ces statues est un Sūrya portant la mitre, sur fond de stèle, conservé aujourd'hui au musée Guimet. Elle a été publiée par Albert Le Bonheur dans son étude

58. Les deux premières statues sont conservées et exposées au musée national de Jakarta, sous les numéros 7974 (64 cm de haut) et 8416 (49 cm de haut). La dernière pièce, très fragmentaire, appartient à la collection du Centre national de la Recherche archéologique à Jakarta $(10 \mathrm{~cm}$ de haut, $17,5 \mathrm{~cm}$ de large, $8 \mathrm{~cm}$ d'épaisseur).

59. Cette pierre rappelle par exemple celle dans laquelle sont sculptées les statues du Bengale. Mais, pour mieux appréhender leurs ateliers de production et leur diffusion, il faudrait pouvoir effectuer des analyses pétrographiques systématiques sur les pierres dans lesquelles sont sculptées les statues mitrées de l'ensemble des sites étudiés ici.

60. Musée national de Jakarta, $n^{\circ} 5074$ ( $c f$. les Notulen de la Bataviaasch Genootschap pour l'année 1916, p.140 et 176). Ce cachet a été publié par L. Malleret (sur les indications de L.-Ch. Damais): il n'a pas manqué de faire remarquer ses affinités avec les intailles trouvées à Óc Eo (1963). 
sur la statuaire indonésienne dans les collections du musée Guimet : il la classe dans l'art de Java central du VII Ie-IXe siècle, mais avec un point d'interrogation ${ }^{61}$. Contrairement aux trois Viṣnu de Cibuaya, qui sont en schiste noir d'importation, cette statue est en andésite, matériau de prédilection des sculpteurs javanais : on doit en déduire qu'il s'agit d'une production locale, peut-être plus tardive, ce qui pourrait expliquer certaines différences stylistiques avec les Viṣnu mitrés étudiés plus haut. Toujours est-il qu'elle ne nous paraît pas appartenir à l'art « classique » de Java.

La deuxième pièce, dont nous n'avons pu encore trouver d'illustration, a été vue et décrite in situ par Sri Suyatmi Satari dans les années 1970 près de la ville de Pekalongan ${ }^{62}$. Il s'agit d'un Viṣnu très érodé (sculpté dans une pierre dont la qualité n'est pas précisée), à quatre bras, tenant la conque, le disque, la massue et un quatrième attribut indistinct. Sa tête porte la mitre et des bijoux ornent ses oreilles; il est flanqué de deux acolytes, ce qui différencie a priori cette pièce de toutes celles relevées jusqu'ici dans la famille des Viṣnu mitrés. Cependant, les disproportions de l'image (membres lourds et grosse tête) rappelaient à l'auteur du rapport le Viṣnu $n^{\circ} 1$ de Cibuaya.

\section{Réseaux marchands, vishnouisme et indianisation}

\section{Le rôle de la péninsule Malaise}

Les États de l'isthme de la péninsule Malaise, favorisés par leur position géographique entre océan Indien et mer de Chine méridionale, ont naturellement servi de relais à la pénétration des influences indiennes vers le Cambodge ou vers Java, modifiant au passage, dès la fin du IVe siècle, l'esthétique des formes voyageuses indiennes ${ }^{63}$. Ceux de la côte ouest constituent un point de départ naturel vers les côtes indiennes ou un atterrage normal après la traversée du golfe du Bengale ; ils sont en relation avec les sites de la côte orientale par des voies trans-péninsulaires aujourd'hui bien repérées ${ }^{64}$. De plus, érigés sur et autour d'importants gisements d'étain et d'or, produits dont on sait le rôle essentiel dans les réseaux transasiatiques de l'époque, ces États ne pouvaient manquer de prendre alors une position centrale dans l'économie de l'Asie du Sud-Est et, en aval, dans le processus d'indianisation de la région.

Parmi ces États, celui que les sources chinoises désignent par le nom de Dunsun et situent dans la région de Chaiya semble bien avoir joué un rôle économique prépondérant. Ces mêmes sources nous apprennent que ses relations commerciales

61. Musée Guimet $n^{\circ} 18239$ (elle y est entrée avec les collections ayant appartenu à l'ancien musée du Trocadéro); $c f$. Le Bonheur 1971, p. 270.

62. Soeyatmi Satari 1978, p. 4 (aucune illustration n'est donnée de cette pièce). Le site est situé dans le district de Tersono, kabupaten de Batang, non loin à l'est de la ville de Pekalongan.

63. P. Dupont notait déjà que les connexions entre les différents groupes d'images supposaient des développements «étrangers au Fou-nan » (1955, p. 67, 114). J. Boisselier (1955, p. 270) propose pour sa part « des origines et des influences communes » pour les statues de ces deux régions.

64. Ces premiers États de la péninsule Malaise, connus surtout encore par les sources étrangères, ont été étudiés en détail dans les travaux de P. Wheatley (1956, 1961 et 1983). On lira aussi avec profit les deux études de synthèse de M. Jacq-Hergoualc'h et al. (1995 et 1996) sur les sites thaïlandais, préparées à partir des données recueillies plus récemment par les archéologues. Nous utilisons ici, par commodité, le terme « État » au sens de «système politique », sans préjuger du niveau d'organisation sociale de l'entité en question (donc sans entrer dans un débat esssentiel, mais peu pertinent pour le sujet qui nous occupe). 
allaient du Tonkin au golfe Persique : on aurait ainsi compté au IIIe siècle dans son port cinq cents foyers de marchands venus du monde iranien (parthes, sogdiens ou persans). Ceci n'est pas, bien sûr, sans nous rappeler que certaines des pièces mitrées examinées plus haut dénotaient des influences venues de cette même région. Ce sont aussi les sources chinoises qui nous révèlent que le Dunsun était passé au III ${ }^{e}$ siècle dans l'orbe du Funan, alors en pleine expansion. Ces liens politiques, attestés ainsi entre la basse vallée du Mékong et la péninsule Malaise, ne peuvent cependant pas expliquer seuls les convergences frappantes entre les images des deux régions : rien ne prouve en effet que de tels liens politiques aient existé par ailleurs entre les États de la péninsule Malaise et ceux de Sumatra ou de Java, ou entre ces derniers et le Funan, alors même que des convergences tout aussi frappantes ont bien été mises en évidence.

Il faut plutôt considérer que ces développements, plus généraux, constituent le prolongement du rôle déjà pionnier de la péninsule Malaise au sein des réseaux d'échange inter-asiatiques. Les recherches archéologiques récentes ont montré en effet que dès la deuxième moitié du 1 rr millénaire av. J.-C., longtemps avant que des formes d'organisation politique ou des religions indiennes n'y soient adoptées - avant donc toute «indianisation»-, des petits États rudimentaires (ou des chefferies) avaient prospéré sur la rive malaise du détroit de Malacca, portés par les échanges internationaux, avec l'Inde en particulier, importatrice d'étain et d'or ${ }^{65}$.

D'autres recherches archéologiques menées ces dernières années sur des sites protohistoriques de la frange côtière de l'Asie du Sud-Est (comme Ban Don Tha Phet en Thaïlande, Kuala Selinsing en Malaysia, Sembiran à Bali, Trà Kiệu au Viêt Nam), ont bien mis en évidence les ramifications de ces réseaux d'échange à l'ensemble de cette région. Tous ces sites ont produit l'un ou l'autre (ou plusieurs) des marqueurs archéologiques caractéristiques de cette période d'échanges intenses qui a précédé puis accompagné la première indianisation de la région, comme le site de Buni dans la baie de Jakarta l'avait fait dans les années 1960 ou ceux du Funan depuis les années 1940 : les céramiques roulettées indiennes ou, plus généralement, les céramiques à pâte fine, les perles en verre et en pierres semi-précieuses, les bols en bronze à haute teneur en étain, les objets en bronze de la culture de Đông Sơn, les objets originaires de la Méditerranée attestent ainsi des relations économiques tissées entre l'océan Indien et la mer de Chine méridionale ${ }^{66}$.

Dans cette optique, l'indianisation de la région, dont témoignent entre autres les images mitrées étudiées ici, apparaît simplement comme une nouvelle étape de la formation de ces premiers États marchands d'Asie du Sud-Est, marquée entre autres par l'adoption nouvelle de pratiques rituelles indiennes et des représentations qui leur sont attachées. Ces statues, qui témoignent d'un culte rendu principalement à Viṣnu, nous fournissent donc indéniablement une belle illustration de l'extension rapide de ces réseaux marchands, à partir des États pionniers de la péninsule Malaise, sur toute la façade occidentale de l'Asie du Sud-Est.

\section{Un art de réseau pan-régional}

Une deuxième constatation s'impose après ce survol des divers groupes régionaux de statues de la famille des Viṣnu mitrés à robe longue. De la basse vallée du Mékong à la

65. Miksic 1991 ; Christie 1990 ; voir aussi Leong Sau Heng 1993. Le point de vue indien sur ces échanges a été largement développé dans les recherches de Himanshu Prabha Ray (1989 et 1994).

66. Voir les références citées dans la note précédente; on se reportera aussi à l'étude de synthèse de I. C. Glover (1989), à l'article de I. C. Glover et Mariko Yamagata (1998) et au récent mémoire de DEA de Bérénice Bellina (Témoignages archéologiques de contacts entre l'Asie du Sud et l'Asie du Sud-Est [VI siècle avant J.-C.-VIc siècle après J.-C.], université Sorbonne nouvelle-Paris III, 1997). 
baie de Jakarta (et peut-être au-delà à Java central), en passant par la péninsule Malaise et l'île de Bangka, entre le tout début du Ve et la fin du VIe siècle, les pièces étudiées cidessus participent toutes d'un même cheminement artistique. Le parallèlisme de leur évolution, pendant deux siècles et sur trois régions distinctes, vient confirmer notre interprétation de ces développements. Les premières images, proches encore des codes indiens de représentation, n'en présentent pas moins dès leur apparition des modifications liées à une production locale, propre à l'Asie du Sud-Est.

Les développements locaux iront parfois en s'accentuant au fur et à mesure que s'épanouissent les ateliers qui maîtrisent désormais parfaitement ces moyens d'expression. Ainsi, au Cambodge, l'apparition progressive des vêtements courts, avec des plis rayonnants et des étoffes en général plus fines, dans quelques pièces de transition, puis dans les arts de Sambor Prei Kuk ou du Phnom Da, semble bien correspondre à une orientation des représentations essentiellement khmère. Cette nouvelle orientation se traduit aussi dans la plastique, avec une morphologie des corps sensiblement modifiée, sans que l'on quitte cependant encore cette famille "mitrée » qui nous occupe ici.

Ailleurs en Asie du Sud-Est, au VII ${ }^{e}$ siècle, ou peut-être même au début du VIIIc siècle pour les pièces les plus tardives, de rares productions attestent d'évolutions parallèles à celles du Cambodge : seule la Thaïlande en fournit des exemples tardifs, à Takuapa sur la péninsule ou à Si T'ep dans la plaine centrale, où l'on trouve le seul exemple de vêtements courts hors du Cambodge. Mais, dans l'ensemble, les ateliers de production des statues mitrées sont bien en nette perte de vitesse au-delà du VIc siècle.

Pendant deux siècles incontestablement, peut-être pendant trois siècles, ces productions doivent donc être qualifiées de pan-régionales : ces formes et leur évolution ne nous semblent pas en effet devoir être associées principalement à un État particulier de la région. Elles sont bien plutôt l'émanation religieuse d'un réseau marchand : les deux aspects - séculier et rituel - apparaissent dès lors comme indissociables.

Dans cette optique aussi, les Viṣnu étudiés ici constituent un excellent marqueur (au sens où les archéologues utilisent ce terme) de cette période de formation des grandes tendances artistiques de la région, qui traduisent pour leur part des développements économiques, sociaux et politiques. Il faudra attendre les VIII et $\mathrm{IX}^{\mathrm{e}}$ siècles, au Cambodge comme à Java, pour qu'apparaissent des formes artistiques résolument localisées, en d'autres termes des arts « nationaux ${ }^{67}$.

En menant ce raisonnement un peu plus loin encore, on doit d'ailleurs distinguer ici trois modes différents de prolongements artistiques pour ces premières statues indianisées de l'Asie du Sud-Est, correspondant aux trois régions qui nous ont principalement occupés dans cet article. Alors que l'art khmer à ses débuts semble largement s'inscrire dans le prolongement des formes artistiques décrites ci-dessus, sans véritable solution de continuité, les arts de cette même famille en péninsule Malaise et à Sumatra ne paraissent pas avoir de prolongements directs dans ce qu'on a parfois qualifié, faute de mieux, "d'art de Sriwijaya » (la diversité et le renouvellement continuel des influences extérieures, et l'incapacité à développer un style qui lui soit propre devraient proscrire cet usage) ${ }^{68}$. Dans la baie de Jakarta, et plus généralement à

67. B. P. Groslier, dans une de ses nombreuses contributions à l'Encyclopaedia Universalis, fut à notre connaissance le premier et le seul à avoir signalé clairement cette rupture de la fin du premier millénaire dans l'évolution des arts de l'Asie du Sud-Est. Il note ainsi qu'au VIII' siècle « les arts nationaux sont constitués » et que, désormais, « l'erreur n'est plus possible entre un bouddha khmer, môn ou javanais, quels que soient leurs ancêtres communs. C'est une autre phase de l'histoire qui commence » (citation d'après la notice « Asie du Sud-Est : expansion de l'art indien », édition CDROM de 1997).

68. On lira par exemple à ce propos l'ouvrage de Subhdradis Diskul (éd.) sur « l'art de Sriwijaya » (1980). Quoi qu'en dise le titre de ce livre, son éditeur scientifique et ses auteurs ont en fin 
Java-Ouest, la production d'images brahmaniques, pour autant qu'on puisse aujourd'hui en juger, est pratiquement stoppée net après le $\mathrm{V}^{\mathrm{e}}$ siècle; la production artistique javanaise se concentrera, à partir du VIIIe siècle seulement, dans ce qu'il est convenu d'appeler l'art « classique » de Java central.

Sans vouloir trop nous attarder ici sur un vaste problème dont les tenants et les aboutissants ne peuvent être encore que très partiellement élucidés, on peut sans doute considérer déjà que ces prolongements artistiques distincts traduisent des conjonctures économiques et politiques divergentes. À la formation des deux grands États plus centralisés des Khmers et de Mataram s'oppose, en ce qui concerne Sriwijaya, l'émergence d'un État éclaté, polycentrique, à vocation essentiellement maritime et commerçante, où le pouvoir politique et économique est concentré dans les cités-États portuaires multiples et cosmopolites de Sumatra et de la péninsule Malaise. Avec l'intensification des échanges et l'élargissement incontestable de l'espace social de Sriwijaya, les sources d'inspiration de la création artistique se diversifient, mais l'instabilité inhérente à ce type d'État portuaire inhibe la formation de styles assurés et persistants qui lui soient propres ${ }^{69}$. Les États khmer et javanais, qui se tournent résolument pour leur survie économique vers l'exploitation agricole du territoire qu'ils contrôlent, ont indéniablement plus de propension à la création de formes artistiques régionales, homogènes et distinctes.

\section{Vishnouisme et indianisation}

Le quasi-synchronisme, dans le courant du $V^{c}$ siècle, de l'apparition des premières images mitrées en péninsule Malaise, dans la basse vallée du Mékong et à Java est révélateur de l'intrusion d'une composante brahmanique dans des réseaux tissés de longue date. Plutôt que de l'un ou l'autre des États la région, on a vu que le développement de cette production artistique constitue l'émanation d'un réseau marchand dont les ramifications s'étendent rapidement à la façade occidentale de l'Asie du Sud-Est.

Une troisième perspective importante nous paraît alors devoir être dégagée par la mise en exergue de ce corpus de statues où domine l'image de Viṣnu. Les représentations de ce dieu sont d'abord dominantes numériquement, comme on l'a vu ; à Kota Kapur, sur le seul site d'Asie du Sud-Est daté d'avant le VII ${ }^{\mathrm{c}}$ siècle où la statuaire est directement associée, dans une fouille contrôlée, à un sanctuaire, la prééminence du culte du dieu Viṣnu est en outre indéniable.

La question est donc de savoir pourquoi ce culte rendu à Viṣnu joue un rôle prééminent au sein de ce réseau. En d'autres termes, qui en sont les acteurs principaux ? Il ne s'agit pas de tenter de déterminer ici leur origine ethnique (indienne - du nord ou du sud - ou sud-est asiatique - môn, khmers ou malais, ou d'autres encore) ; cette question n'a pas vraiment de sens dans le milieu éminemment cosmopolite des réseaux maritimes de l'Asie du Sud-Est, car tous sont probablement présents, en proportions et à des titres variables selon les lieux et les époques. Quelle que soit leur origine, il se

\footnotetext{
de compte décidé de ne pas présenter une synthèse sur la question, mais plutôt de conserver une division purement géographique des productions artistiques des divers pays regroupés dans l'orbe de Stiwijaya (Indonésie occidentale, Malaisie, Thaïlande et, accessoirement, Philippines). L'expression «art de Sriwijaya » n'a donc plus là l'ambition de définir un style, mais seulement de regrouper les productions de la période de Sriwijaya (VII'-XIII ${ }^{\mathrm{c}}$ siècles).

69. Pour une analyse récente de la structure de l'État de Sriwijaya, on se reportera à P.-Y. Manguin (sous presse).
} 
trouve que ces acteurs - marchands, religieux et à leur suite des souverains locaux pratiquent désormais un hindouisme particulier qu'il conviendrait de mieux déterminer.

$O$.W. Wolters a déjà mis en évidence le rôle des cultes de dévotion shivaïtes dans la vie politique du Cambodge du VII e siècle. P. Wheatley a étendu pour sa part cette réflexion à l'ensemble de la région : si des références au culte de Siva apparaissent dans l'épigraphie dès la deuxième moitié du IV' siècle au Campā et vers la fin du Vc siècle au Funan, il n'y est fait allusion à la bhakti shivaïte qu'à partir du VIIc siècle, au Cambodge. On sait bien par ailleurs la place prééminente que prendra Śiva dans les pratiques religieuses de toute l'Asie du Sud-Est à partir du VIII' siècle $^{70}$.

Cependant, c'est dans un contexte clairement vishnouite, à l'occasion d'un rituel royal lié à la consécration d'une image des pieds de Viṣnu, qu'apparaît au Funan la mention explicite la plus ancienne de cultes de dévotion en Asie du Sud-Est, dans la deuxième moitié du Ve siècle au plus tard : l'inscription de Gunavarman (K5) à Tháp Mười, dans le delta du Mékong, constitue la première référence à la bhakti et aux bhägavata en Asie du Sud-Est ${ }^{71}$. Que le terme bhāgavata ait alors désigné une secte vaiṣnava indépendante, comme l'accepte $\mathrm{K}$. Bhattacharya, ou qu'il s'applique plutôt à un milieu de brahmanes locaux, issus de l'hindouisme smärta postulé par M. Biardeau vers les débuts de l'ère chrétienne (une religion de dévotion, antérieure aux premières divisions sectaires, qui englobe vishnouisme et shivaïsme, mais où Viṣnu est dominant), il n'en reste pas moins que c'est à des cultes vishnouites qu'il est fait ici référence ${ }^{72}$.

On a vu aussi que les inscriptions de l'État de Tārumānāgara, dans la baie de Jakarta, datées paléographiquement du milieu du $V^{c}$ siècle, faisaient de même allusion au vishnouisme : deux de ces inscriptions représentent des empreintes de pieds, mais elles sont dites dans le texte avoir été laissées par les pieds du roi lui-même, qui est comparé ainsi à Vișnu ; un symbole shivaïte est également gravé sur la pierre ; elles associent enfin des brahmanes aux rituels de consécration d'un projet hydraulique. C'est cependant dès le III siècle, si l'on en croit les sources chinoises, que la présence de brahmanes est attestée au Dunsun, sur l'isthme de la péninsule Malaise ${ }^{73}$.

L'implantation de cultes vishnouites dans l'ouest de Java précède la fondation du temple de Kota Kapur d'environ un siècle : il n'y a donc pas synchronisme parfait entre la statuaire trouvée sur ces deux sites. Les sites de Java-Ouest ont connu dans le courant $\mathrm{du} \mathrm{V}^{\mathrm{c}}$ siècle des développements politiques et économiques importants contemporains de ceux de la péninsule Malaise et de la vallée du Mékong, attestés par une épigraphie sanskrite abondante. À en juger par les seules statues connues à ce jour, le vishnouisme ne semble cependant pas à première vue y avoir connu de succès durable. Le site de Kota Kapur, comme on l'a vu plus haut, s'inscrit pour sa part dans une tout autre

70. Wolters 1979 ; Wheatley 1983 , p. 289-303, où l'on lira le traitement le plus complet à ce jour de la question de l'apparition des brahmanes et du brahmanisme dans les premiers États d'Asie du Sud-Est ; voir aussi Bhattacharya 1961 et 1970. On lira aussi Bosch 1961 pour ses remarques sur la dévotion shivaïte en Indonésie (en particulier les p. 16-18).

71. Cœdès 1931 ; Bhattacharya 1961, p. 97 ; voir aussi Jaiswal 1981, p. 226-228, Chhabra 1935, p. 52-53 et Cœdès 1964, p. 116-118.

72. Ce brahmanisme smārta est décrit, entre autres, dans Biardeau 1994, p. 1-5. Peut-être doit-on trouver aussi dans le panthéon brahmanique des sites sud-est asiatiques décrits ci-dessus (où des images de Viṣnu sont associées à celles de Durgā, de Sūrya, de Siva et plus rarement de Gaṇeśa), un reflet tardif de cet hindouisme smärta?

73. On connaît en Inde d'autres exemples où ce sont les pieds du roi déifié qui sont vénérés (Bakker 1991, p. 25). On peut ajouter ici que c'est à un rituel brahmanique qu'il est fait allusion, dans l'une des interprétations proposées pour la stèle sanskrite de Võ Canh (près de Nha Trang, sur la côte du Viêt Nam), datée peut-être du HII siècle et émanant peut-être d'un roi lié au Funan (voir Chhabra 1935 , p. 45-47 et 32-34 pour des arguments supplémentaires en faveur de la présence du vishnouisme en Asie du Sud-Est, mais que J. Filliozat [1969] juge imprudents, tout en acceptant qu'il s'agit bien de brahmanisme). 
conjoncture historique : il est le sanctuaire, probablement central, de l'un de ces nouveaux petits États émergeant entre le $\mathrm{V}^{e}$ et le VII ${ }^{c}$ siècles sur la côte orientale de Sumatra, dont la coalescence donnera naissance vers 670-680 au puissant État à vocation maritime de Sriwijaya, dont le souverain est adepte du bouddhisme. Si ce nouveau venu prend la peine d'y ériger en 686 une inscription vouant aux gémonies toute personne qui ne lui obéirait pas, c'est que ce site présentait encore en cette fin de VII'c siècle une menace. Le fait que cette même inscription précise en outre qu'elle a été dressée à l'occasion du lancement d'une expédition vers le pays de Java, « qui n'est pas soumis », laisse penser que le nouveau pouvoir en place à Palembang, en s'en prenant à Kota Kapur et, dans la foulée, à un lieu indéterminé de l'île de Java, cherche bien à écarter les réseaux vishnouites de la scène économique : le bhümi $J \bar{a} v a$ de l'inscription pourrait alors bien désigner l'Ouest de Java, où s'étaient précédemment installés les sectateurs de Viṣnu, dans la baie de Jakarta. Il se pourrait donc qu'ils y soient encore assez actifs en cette fin de VII e siècle pour faire de l'ombre, comme ceux de Kota Kapur, au nouveau pouvoir expansionniste de Sumatra.

En l'absence de données assez complètes, tout au plus peut-on à ce jour constater que les sectateurs de Viṣnu jouent aussi un rôle important au sein des réseaux commerciaux de l'Indonésie occidentale, entre le $V^{c}$ et le VIIc siècles. Il est probable que les progrès de la recherche archéologique dans la région révèleront d'autres sites comparables, comme le laissent supposer les éléments disparates relevés plus haut pour Java central ; seuls ces maillons aujourd' hui manquants nous permettront d'affiner notre analyse.

À la lumière des données nouvelles proposées ci-dessus, cette composante vishnouite nous paraît devoir désormais être mise en parallèle avec la composante bouddhique qui se fait jour à peu près à la même époque en Asie du Sud-Est, et en particulier au Funan, sur des réseaux d'échanges en partie superposables ${ }^{74}$. Au même titre que les adeptes du bouddhisme, les vishnouites auraient ainsi joué un rôle moteur dans le processus d'indianisation de l'Asie du Sud-Est, dans les États de la péninsule Malaise d'abord, puis, comme par ricochet, dans la péninsule Indochinoise surtout et, en mineure, vers l'archipel indonésien.

Sans avoir la prétention d'approfondir ici l'étude des modalités diverses de la participation des vishnouites à l'indianisation de l'Asie du Sud-Est - faute de place et surtout de compétence - il nous paraît utile néanmoins de présenter quelques arguments supplémentaires pour appuyer cette perspective nouvelle ${ }^{75}$. On a souvent écrit que si les adeptes du bouddhisme avaient pu jouer un rôle aussi dynamique dans les réseaux marchands du golfe du Bengale, c'est, en simplifiant, qu'en adoptant cette croyance nouvelle, ils rejetaient l'un des concepts fondateurs de la société brahmanique, la notion d'appartenance à une caste donnée, et par là même se donnaient la liberté de voyager au-delà des frontières de l'Inde, sans craindre les souillures induites par le contact avec des personnes d'un statut rituel inférieur. Croyance universaliste, le bouddhisme avait par ailleurs vocation à s'étendre au-delà des frontières de son pays

74. La diffusion d'un premier art bouddhique sur ces mêmes réseaux d'Asie du Sud-Est est mieux connue, du fait qu'on a depuis longtemps associé le bouddhisme au commerce maritime et au dynamisme des sociétés indiennes de l'époque, comme l'avait déjà si bien suggéré Sylvain Lévi (1929). L'ouvrage récent de Himanshu Phraba Ray (1994) met bien cet aspect en perspective. Il n'en reste pas moins qu'il reste à faire une étude comparative systématique des images bouddhiques mises au jour dans la vallée du Mékong, en péninsule Malaise (des deux côtés de la frontière), à Sumatra, à Java et à Kalimantan entre le ve et le VII $\mathrm{V}^{\mathrm{e}}$-VIII ${ }^{\mathrm{e}}$ siècles. Nous nous proposons de le faire dans une prochaine étude.

75. Nous avons largement puisé pour ces passages dans la lumineuse notice consacrée au vishnouisme par André Couture (1997) dans L'encyclopédie des religions et dans l'article de Catherine Clémentin-Ojha et Marc Gaborieau (1994). 
d'origine : religion missionnaire, prosélyte, on sait bien la place qu'elle a prise dans l'Asie toute entière.

Les vishnouites croient pour leur part en un dieu absolu et universel : ils sont donc par définition portés, comme les bouddhistes, au prosélytisme, y compris au-delà des frontières de l'Inde ; les doctrines universalistes de la bhakti permettent à tous d'atteindre le salut (qui ne dépend plus de la naissance dans les seules hautes castes). En Inde même, les vishnouites paraissent bien avoir été les moins affectés par les limites imposées par le système des castes, qu'ils réduisent en quelque sorte à un fait social. Lors de développements ultérieurs du sectarisme, les vishnouites ont ainsi constitué le vecteur de forces d'intégration et d'assimilation, en proposant des formes de dévotion accessibles à tous, même à des non-brahmanes. Ceci explique probablement en partie que les sectes vishnouites, en Inde aujourd'hui encore, soient parmi celles qui sont le plus liées aux milieux marchands.

Parmi les facteurs ayant pu favoriser l'expansion locale du vishnouisme pendant la période de la première indianisation de l'Asie du Sud-Est, on doit enfin ajouter que le dieu Viṣnu est très tôt associé, en Inde-même, à la royauté et au pouvoir politique : il a pu ainsi être aisément adopté par les souverains des nouveaux États de l'Asie du SudEst en cours d'indianisation pour contribuer à assurer leur domination sur des pairs non encore convertis.

Au vu de ces divers arguments, qu'il conviendrait bien sûr d'approfondir, il nous paraît donc légitime de proposer ici d'accorder aux adeptes de Viṣnu un rôle actif dans ces réseaux marchands d'Asie du Sud-Est et donc dans le processus d'indianisation de la région, comme on l'a fait auparavant pour les bouddhistes. Les Vaiṣnava auraient tenu ce rôle pendant une période assez brève, laissant la place à partir du VII ${ }^{\mathrm{c}}$ siècle à des cultes brahmaniques à dominante shivaïte (c'est-à-dire à une autre tradition sectaire de l'hindouisme, à vocation prosélyte elle aussi).

\section{Abstract}

Mitred Viṣnus and trade networks in Southeast Asia: new archaeological data on the 1st millennium A.D.

New archaeological research carried out on three different fronts (history of early Cambodian art, excavations at Kota Kapur, South Sumatra, and at Cibuaya, West Java) revealed hitherto unsuspected links between a series of sites that have at least one common characteristic : they all produced statues of Viṣnu wearing a mitre and a long robe, that can be grouped on stylistic grounds into one single family. The chronology of this panSoutheast Asian family is reconsidered here in the light of the new finds : their anteriority to the Early Khmer art style of Phnom Da is demonstrated ; all of its pieces can now be securely dated from the early Vth to the early VIIth centuries. On the Indochinese peninsula, in what is now Cambodia and Viêt Nam, they are therefore associated with the last two centuries of the Funan polity, rather than with Early Khmer art forms. The central and pioneer role of the Malay peninsula, where the earliest statues (those closest to Indian prototypes) were found, is however emphasized in the study. Rather than to one specific «national » polity, the production of this family of statues is therefore associated with a trade network regrouping a number of archaeological sites on the Western maritime façade of Southeast Asia. Finally, this network is identified as being of Vaisnava obedience. The role played by this Brahmanical sect in the Indianization of Southeast Asia during the period considered is then compared to that played by Buddhism. 


\section{APPENDICE}

\section{Analyses plastiques des principales images indonésiennes}

\section{Les Visnu de Kota Kapur $\left(n^{\circ} 2, n^{\circ} 3\right.$ et $\left.n^{\circ} 4\right)$}

Une statue de Visnu $\left(n^{\circ} 2\right)$, incomplète, a été trouvée en plusieurs morceaux pendant les fouilles de 1994-96. En mauvais état de conservation, sa partie inférieure est brisée et manquante ; la cassure, à la surface irrégulière, est située sous les pectoraux. La partie haute est brisée en plusieurs endroits (épaule, bras, poignets et arc transverse de soutien). Une mitre basse, bordée d'un liseré saillant, coiffe cette divinité. Comme pour le Vișnu $n^{\circ} 3$, des boucles en anglaises sont figurées sur la nuque. Un arc transverse relie l'arrière de la mitre aux deux attributs portés dans chaque main. Le visage lunaire présente des traits sculptés avec soin : un front bas, des arcades sourcilières arquées et non jointives, un nez fin, des joues rondes uniformément lisses, des lèvres fines aux commissures droites et un menton court, à la houppe arrondie. Les oreilles, très étirées, ont l'anthélix ourlé. Le cou, large et cylindrique, est peu dégagé ; les épaules sont arrondies et le torse, bien que brisé, parâit très étroit, avec des pectoraux peu développés; les bras sont harmonieux et leurs masses musculaires sont bien suggérées.

Le Viṣnu $n^{\circ} 3$, la plus grande et la plus complète des quatre pièces de Kota Kapur, représente le dieu debout, à quatre bras. Le corps de la statue est brisé en trois fragments qui se raccordent parfaitement. Les bras manquent en partie : les bras gauches sont brisés sous l'aisselle, le bras droit antérieur au-dessus du coude et le bras droit postérieur sous le poignet. Une main droite tenant la terre appartient vraisemblablement à cette statue. Les pieds, brisés, ont été trouvés pendant la fouille de 1996 et l'on peut donc relier sans solution de continuité le corps de la statue à son socle à tenon. L'extrêmité de la massue vient s'encastrer sur le socle, à gauche des pieds.

Une haute mitre cylindrique, lisse, coiffe cette représentation au traitement plastique soigné. L'arrière de la mitre montre une partie d'un arc transverse de soutien. La chevelure est figurée par le bord inférieur de la coiffe qui dépasse de la mitre et borde la partie supérieure du front. Des boucles en anglaises sont figurées sur la nuque. Le cadre du visage est ovale, le front est peu dégagé, les arcades sourcilières sont courbes, en léger relief. Le dessin des yeux est gravé et les paupières sont indiquées par un léger bombé. Le nez est droit, fin, les joues sont rondes sans figuration des pommettes et la bouche, sommairement sculptée, esquisse un léger sourire. Les oreilles, bien observées, ont l'anthélix ourlé et les lobes étirés. Le cou est cylindrique sans indications anatomiques ou de plis gravés. La base du cou est indiquée par une ligne courbe fortement creusée.

Les épaules sont larges et puissantes. Ce qui reste des bras montre un modelé harmonieux et des masses musculaires visibles et situees à leurs emplacements naturels. Le point d'attache des bras multiples est l'épaule qui reste harmonieuse. Le dos est lisse, avec un sillon vertébral exact ; le creux des reins est marqué. Le torse est bien observé, avec des pectoraux légèrement bombés. La courbe épigastrique sépare nettement le thorax et l'abdomen. La région abdominale est traduite avec naturalisme, un léger bourrelet audessus de la taille traduit la vérité des chairs. Le galbe de la partie inférieure du corps est visible à travers le vêtement, la saillie des fesses et le bombé du haut des cuisses sont apparents. Le vêtement est indiqué par des lignes gravées concentriques partant d'un pan médian de tissu en saillie. La partie postérieure du vêtement est incisée de lignes horizontales courbes.

La statue masculine $n^{\circ} 4$ de Kota Kapur, conservée depuis les années 1930 au musée national de Jakarta, présente également un fort mauvais état de conservation : la partie inférieure du corps est manquante (la cassure sinueuse, à la surface irrégulière, est située au-dessus de la taille); les bras sont manquants (les bras droits sont brisés à la racine de l'épaule tandis que ceux du côté gauche le sont sous l'aisselle); des éclats divers sont répartis sur l'ensemble du visage (joue droite, nez, lèvres et menton). La mitre, particulièrement basse, est bordée d'un liseré large et saillant sur le front. Le cadre du visage est ovale, le front est droit, peu dégagé, les arcades sourcilières sont courbes, le nez 
présente des narines dilatées et le menton dessine une houppe proéminente. Les oreilles, à l'anthélix ourlé, sont parées d'anneaux lisses dont la surface est érodée. Un nimbe, ovale et de petite taille, est placé à l'arrière de la tête. Ce qu'il reste du corps montre un cou cylindrique au léger relief de la trachée, des épaules et un torse étroit et une taille haute et excessivement serrée.

\section{Les Viṣnu de Cibuaya $\left(n^{\circ} 1\right.$ et $\left.n^{\circ} 2\right)$}

Le Viṣnu $n^{\circ} 1$ est debout, de position statique, à quatre bras. Cette œuvre est traitée en plaque sculptée plutôt qu'en ronde bosse. Un large nimbe incisé de stries rayonnantes est placé à l'arrière de la tête. Des réserves de pierre sont visibles à différents endroits (entre les bras et la taille, entre les jambes, etc.). La mitre haute, de forme légèrement tronconique, est décorée sur sa face antérieure de deux larges fleurs ouvertes encadrées de bandes rectilignes perlées. La base de la mitre est bordée d'un liseré lisse. Le visage, d'un contour ovale, présente des traits bien dessinés (arcades sourcilières courbes, yeux largement ouverts à la caroncule ourlée, nez droit aux narines dilatées, bouche courte, aux lèvres espacées l'une de l'autre et aux commissures droites, oreilles ourlées aux lobes étirés). Les proportions sont tassées, ce qui accentue la plastique raide du corps. Le cou, incisé de plis gravés, est peu dégagé. Les épaules sont hautes, carrées et les bras courts, assez robustes. Les poignets larges sont enserrés de bracelets en anneaux lisses. Les mains, petites, ont des doigts schématiquement traités et mal séparés les uns des autres; elles tiennent les attributs attendus (conque, disque, terre et massue). Le torse, étroit et sans relief, est orné sur sa partie supérieure d'un large collier et la taille est marquée. La région abdominale est peu naturaliste et ne présente aucune indication de bourrelet de chair; le nombril est figuré par un large creux. Le bassin est raide et les jambes sont droites, au traitement sommaire.

Le Viṣnu $n^{\circ} 2$ est une stèle à la partie supérieure courbe : les deux bras postérieurs et attributs du dieu marquent les bords supérieurs du chevet. Une haute et large mitre, sculptée d'un motif indistinct sur sa face antérieure, coiffe une tête ronde. Les traits du visages paraissent très indiens : le front est bas, les arcades sourcilières dessinent une courbe marquée, le nez est fin, les joues charnues, la bouche courte aux lèvres entrouvertes et le menton très rond. Le contour des oreilles est mal délimité, les lobes sont ornés d'épaisses boucles qui retombent sur les épaules. Le torse est puissant, les épaules larges et les bras souples, la main antérieure droite est tournée, paume placée vers l'avant alors que la main antérieure gauche enserre la massue sous le pommeau. Les bras et mains postérieurs sont atrophiés tant ils sont courts et larges, les masses charnues de l'intérieur des mains sont excessivement développées. Les attributs tenus dans les mains postérieures sont également d'une taille exagérée. Le galbe des jambes est apparent sous l'étoffe fine et incisée de lignes courbes (les bords du vêtement se poursuivent sur les côtés des jambes).

\section{ABRÉVIATIONS UTILISÉES DANS LE TEXTE ET LA BIBLIOGRAPHIE}

$\begin{array}{ll}\text { BKI } & \text { Bijdragen tot de Taal-, Land-en Volkenkunde van de Koninklijk Instituut, Leiden } \\ \text { DCA } & \text { dépôt de la Conservation d'Angkor } \\ \text { EFEO } & \text { École française d'Extrême-Orient } \\ \text { MG } & \text { musée Guimet } \\ \text { MNPP } & \text { musée national de Phnom Penh } \\ \text { AA } & \text { Arts asiatiques, Paris } \\ \text { Art. Asiae } & \text { Artibus Asiae. Institute of Fine Arts, New York University, Ascona. } \\ \text { BEFEO } & \text { Bulletin de l'École française d'Extrême-Orient, Paris } \\ \text { OV } & \text { Oudheidkundig Verslag, Bataviaasch Genootschap, Batavia } \\ \text { PEFEO } & \text { Publications de l'École française d'Extrême-Orient, Paris } \\ \text { VKI } & \text { Verhandelingen van de Koninklijk Instituut van Taal-, Land- en Volkenkunde, Leiden. }\end{array}$




\section{RÉFÉRENCES BIBLIOGRAPHIQUES}

ARDIKA, I Wayan

1998 «Early evidence of Indian contact with Bali », in P.-Y. Manguin (éd.), Southeast Asian Archaeology 1994, Hull, University of Hull, Centre for Southeast Asian Studies, p.139-145.

ARDIKA, I Wayan et BELLWOOD, P.

1991 «Sembiran: The beginning of Indian contact with Bali », Antiquity, 65, p. 221-232.

BAKKER, $\mathbf{H}$.

1991 "The Footprints of the Lord» in D. L. Eck et F. Mallison, Devotion divine. Bhakti traditions from the regions of India, Groningen/Paris, E. Forsten/EFEO

BÉNISTI, M. (Groningen Oriental Studies, vol. 8), p. 19-38.

1970 Rapports entre le premier art khmer et l'art indien, Paris, EFEO (Mémoires archéologiques 5), 2 vol.

BHATTACHARYA, Kamaleswar

1961 Les religions brahmaniques dans l'ancien Cambodge d'après l'épigraphie et l'iconographie, Paris, EFEO (PEFEO 49).

1970 « Religious speculations in Ancient Cambodia (Saiva speculations)», in H.B. Sarkar (ed.), R.C. Majumdar Felicitation Volume, Calcutta, K.L. Mukhopadhyay, p.78-97.

BIARDEAU, $\mathrm{M}$.

1994 Études de mythologie hindoue, II : bhakti et avatāra, Paris, EFEO (PEFEO 171).

BOISSELIER, J.

1955 La statuaire khmère et son évolution, Saigon, EFEO (PEFEO 37), 2 vol.

1959 «Le Visnu de Tjibuaja (Java occidental) et la statuaire du Sud-Est asiatique », Art. Asiae, 22, p. 210-226.

1959a «La statuaire préangkorienne et Pierre Dupont », $A A, 6$, p. 59-69.

1974 La sculpture en Thaillande, Fribourg, Office du Livre.

1986 Il Sud-Est asiatico, Turin, Storia universale dell' arte.

1989 Trends in Khmer Art, Ithaca, Cornell University Press, Southeast Asia Program.

BOSCH, F.D.K.

1961 «The Problem of Hindu Colonisation of Indonesia », in F.D.K. Bosch, Selected Studies in Indonesian Archaeology, La Haye, Martinus Nijhoff, p. 23-46

CASPARIS, J.G. de

1956 Prasasti Indonesia, II : Selected Inscriptions from the 7th to the 9th Century A.D., Bandung.

1986 «Some Notes on the Oldest Inscriptions of Indonesia », in C.M.S. Hellwig \& S.O. Robson (éd.), A Man of Indonesian Letters : Essays in Honour of Professor

A. Teeuw, Dordrecht, Cinnaminson (VKI 121), p. 242-256.

CHHABRA, B. Ch.

1935 «Expansion of Indo-Aryan Culture during Pallava Rule, as Evidenced by Inscriptions », Journal of the Asiatic Society of Bengal, 1, p. 1-64.

CHRISTIE, J. Wisseman

1990 "Trade and state formation in the Malay Peninsula and Sumatra, 300 B.C. - A.D. $700 »$ in J. Kathirithamby-Wells \& J. Villiers (éd.), The Southeast Asian Port and Polity : Rise and Demise, Singapore, Singapore University Press, p.39-60.

1995 « State formation in Early Maritime Southeast Asia : A consideration of the theories and the data », BKI, 151, p. 235-288.

CLÉMENTIN-OJHA, C. et GABORIEAU, M.

1994 «La montée du prosélytisme dans le sous-continent indien : Introduction », Archives des sciences sociales et des religions, 39(87), p. 13-34. 
CEDÈs G.

1918 «Le Royaume de Çrivijaya », BEFEO, 18, p. 1-36

1942 Inscriptions du Cambodge, Hanoi, EFEO (Collection de textes et documents sur l'Indochine, vol. II).

1928 Les collections archéologiques du Musée national de Bangkok, Paris, Ars Asiatica, 12.

1930 «Les inscriptions malaises de Çrivijaya », BEFEO, 30, p. 29-80.

1931 «Deux inscriptions sanskrites du Fou-nan », BEFEO, 31, p. 8-11.

1964 Les États hindouisés d'Indochine et d'Indonésie, Paris, De Boccard.

COUTURE, A.

1997 «Le vishnouisme », in F. Lenoir \& Y.T. Masquelier (ed.), Encyclopédie des

DAGENS, B.

1993 «Le voyage en Orient, ou à chacun sa beauté», Atlas de l'art, Paris, Encyclopaedia Universalis, p. 310 .

DAMAIS, L.-Ch.

1959 «Le bouddhisme en Indonésie », France-Asie ( ${ }^{\circ}$ spécial : Présence du bouddhisme), p. 153-157, p. 813-828.

DUPONT, $P$.

1941 «Les Visnu mitrés de l'Indochine occidentale », BEFEO, 41(2), p. 233-254.

1951 «es premières images brahmaniques de l'Indochine », BSEI, 26(2) p. 131-140.

1955 La statuaire préangkorienne, Ascona, Artibus Asiae (Supplementum XV).

FERDINANDUS, Sri Utami

1995 «Arca-arca Wisnu di Asia Tenggara (Abad ke 4-8 M.) », in Manusia dalam ruang : Studi kawasan dalam arkeologi, Jakarta, (Berkala Arkeologi, 15), 1995,

FILLIOZAT, J. p. $185-192$.

1969 «'inscription dite de Vo Canh », BEFEO, 55, p. 117-124.

GITEAU, M.

1965 Les Khmers : sculptures khmères, reflets de la civilisation d'Angkor, Paris,

GLOVER, I.C. Bibliothèque des Arts.

1989 Early Trade between India and Southeast Asia : A link in the development of a World Trading System, Hull, University of Hull, Centre for Southeast Asian Studies, Occasional paper, $\mathrm{n}^{\circ} 16$.

GLOVER, I.C. et MARIKO YAMAGATA

1998 «Excavations at Tra Kieu, Vietnam : Sa Huynh, Cham and Chinese influences », in P.-Y. Manguin (éd.), Southeast Asian Archaeology 1994, Hull, University of

GOLOUBEW, J. Hull, Centre for Southeast Asian Studies, p. 75-93.

1940 «Les images de Sūrya au Cambodge », Cahiers de l'EFEO, 22, p. 38-42.

GROSLIER, B. P.

1995 «L'Asie du Sud-Est», in A. Châtelet \& B. P. Groslier (éd.), Histoire de l'art,

HARLE, J.C. Paris, Larousse (In extenso), $2^{\mathrm{e}}$ édition révisée (1 ${ }^{\text {re }}$ édition 1985).

1974 Gupta sculpture: Indian sculpture of the 4th and 6th centuries A.D., Oxford, Clarendon Press.

1986 The Art and Architecture of the Indian Subcontinent, Harmondsworth, The Pelican History of Art.

HEIDHUES, M. F. Somers

1992 Bangka tin and Mentok pepper: Chinese settlement on an Indonesian island, Singapore, ISEAS. 
JACQ-HERGOUALC'H, M. et al.

1995 «Une cité-État de la péninsule Malaise : le Langkasuka », $A A, 50$, p. 47-66.

1996 «La région de Nakhon Si Thammarat (Thaillande péninsulaire) du $V^{\mathrm{c}}$ au XIV siècle », Journal asiatique, 284(2), p. 361-435.

JAISWAL Suvira

1981 The origin and development of Vaiṣnavism, New Delhi, Munshiram Manoharlal, 2nd rev. ed.

KOESTORO, LUCAS P., P.-Y. MANGUIN et SOEROSO M.P.,

1998 «An ancient site reascertained: The 1994 campaign at Kota Kapur (Bangka, South Sumatra), in P.-Y. Manguin (éd.), Southeast Asian Archaeology 1994 : Proceedings of the Fifth International Conference of the European Association of Southeast Asian Archaeologists, Hull, University of Hull, Centre for Southeast Asian Studies, vol.II (sous presse).

KULKE, $\mathrm{H}$.

1993 « Kadatuan Srivijaya - Empire or Kraton of Srivijaya ? A Reassessment of the Epigraphical Evidence », BEFEO, 80, p. 159-181.

LE BONHEUR, A.

1971 La sculpture indonésienne au musée Guimet. Catalogue et étude iconographique, Paris, Publications du musée Guimet.

LEONG SAU HENG

1993 «Ancient trading centres in the Malay Peninsula », Jurnal Arkeologi Malaysia, 6, p. 1-9.

LÉVI, S.

1929 «Les 'marchands de mer' et leur rôle dans le bouddhisme primitif », Bulletin de l'Association française des Amis de l'Orient, 7, p. 19-39.

MALLERET, L.

1937 Musée Blanchard de la Brosse, Saigon. Catalogue général des collections, tome I: Arts de la famille indienne, Hanoi, Imprimerie d'Extrême-Orient, 1937.

1959-63 Archéologie du delta du Mékong, Paris, EFEO, (PEFEO 43), 4 tomes en 7 vol.

1963 « Notes archéologiques, II : Pierres gravées et cachets de divers pays du sud-est de l'Asie », BEFEO, 51(1), p. 99-116.

1966 «Une nouvelle statue préangkorienne de Sūrya dans le Bas-Mékong », in Ba Shin, J. Boisselier \& A.B. Griswold (éd.), Essays offered to G.H. Luce, Ascona, Artibus Asiae (Supplementum 23), vol.II, 1966, p. 109-120.

MANGUIN, P.-Y.

1987 «Palembang et Sriwijaya: Anciennes hypothèses, recherches nouvelles », $B E F E O, 76$, p. 337-402.

1992 «Excavations in South Sumatra, 1988-1990: New evidence for Sriwijayan sites », in I. C. Glover (éd.), Southeast Asian Archaeology 1990 : Proceedings of the Third Conference of the European Association of Southeast Asian Archaeologists, Hull, University of Hull, Centre for Southeast Asian Studies, p. 63-73.

1993 «Palembang and Sriwijaya : an early Malay harbour-city rediscovered », Journal of the Malayan Branch, Royal Asiatic Society, 66(1), p. 23-46.

sous presse « The amorphous nature of coastal polities in Insular Southeast Asia : Restricted centres, extended peripheries », in M. Charras (éd.), Beyond the State: Sociospatial structuration in Southeast Asia, Paris, LASEMA-CNRS.

MCKINNON, E. E., HASAN DJAFAR et SOEROSO M.P.,

1998 «Tarumanagara? : A note on discoveries at Batujaya and Cibuaya, West Java », in P.-Y. Manguin (éd.), Southeast Asian Archaeology 1994, Hull, University of Hull, Centre for Southeast Asian Studies, vol. I, p. 147-159.

MIKSIC, J.

1991 «Settlement patterns and sub-regions in Southeast Asian History », Review of Indonesian ans Malay Affairs, 31 (1), p. 86-144. 
O'CONNOR, S.J.

1972 Hindu Gods of Peninsular Thailand, Ascona, Artibus Asiae Publishers.

PARMENTIER, $\mathrm{H}$.

1927 La statuaire khmère et son évolution, Paris, EFEO (PEFEO 37), 2 vol.

PIRIYA KRAIRIKSH

1980 Art in Peninsular Thailand prior to the Fourteenth Century A.D., Bangkok, The Fine Arts Department.

PORADA, E.

1963 L'Iran ancien, Paris, Albin Michel.

RAO, Gopinatha

1914-16 Elements of Hindu Iconography, Madras, 2 vol.

RAY, Himanshu Prabha

1989 «Early maritime contacts between South and Southeast Asia », Journal of Southeast Asian Studies, 20(1), p. 42-54.

1994 The winds of change: Buddhism and the maritime links of Early South Asia, Delhi, Oxford University Press, 1994.

SOEYATMI SATARI

1978 New finds in Northern Central Java, Jakarta, Pusat Penelitian Purbakala dan Peninggalan Nasional (Bulletin of the Research Center of Archaeology of Indonesia, 13).

STUTTERHEIM, W.F.

1937 « Note on a newly found fragment of a four-armed figure from Kota Kapur (Bangka) », Indian Arts and Letters, 11, p. 105-109.

SUBHADRADIS DISKUL (éd.)

1980 The art of Śrivijaya, Kuala Lumpur / Paris, Oxford University Press / UNESCO, 1980.

SUTJIPTO WIRJOSUPARTO

1963 «The second Visnu-Image of Cibuaja in West Java », Madjalah Ilmu-ilmu Sastra Indonesia, 1(2), p.170-187.

VOGEL, J.-Ph.

1925 «The Earliest Sanskrit Inscriptions of Java», in Publicaties van de Oudheidkundige Dienst in Nederlandsch-Indië, 1, p. 15-35.

WALES, H.G. QUARITCH

1961 The making of Greater India : A Study in South-East Asian Culture, Londres, Change, 2 éd. révisée.

WALKER, M.J. et SANTOSO SUGHONDO

1977 « Romano-Indian rouletted pottery in Indonesia », Mankind, 11, p. 39-45.

WHEATLEY, P.

1956 《Tun-sun », JRAS, 1956, p. 17-30

1961 The Golden Khersonese: Studies in the Historical Geography of the Malay Peninsula before A.D. 1500, Kuala Lumpur, Oxford University Press.

1983 Nägara and Commandery : Origins of the Southeast Asian Urban Traditions, WILLIAMS, J. Chicago, University of Chicago, Department of Geography.

1982 The Gupta art in India : Empire and Province, Princeton University Press. WOLTERS, O.W.

1967 Early Indonesian Commerce : A Study of the Origins of Sri Vijaya, Ithaca, Cornell University Press.

1979 « Khmer 'Hinduism' in the seventh century », in R.B. Smith et W. Watson (éd.) Early South East Asia : Essays in archaeology, history and historical geography, Oxford / New York / Kuala Lumpur, Oxford University Press, p. 427-456. 


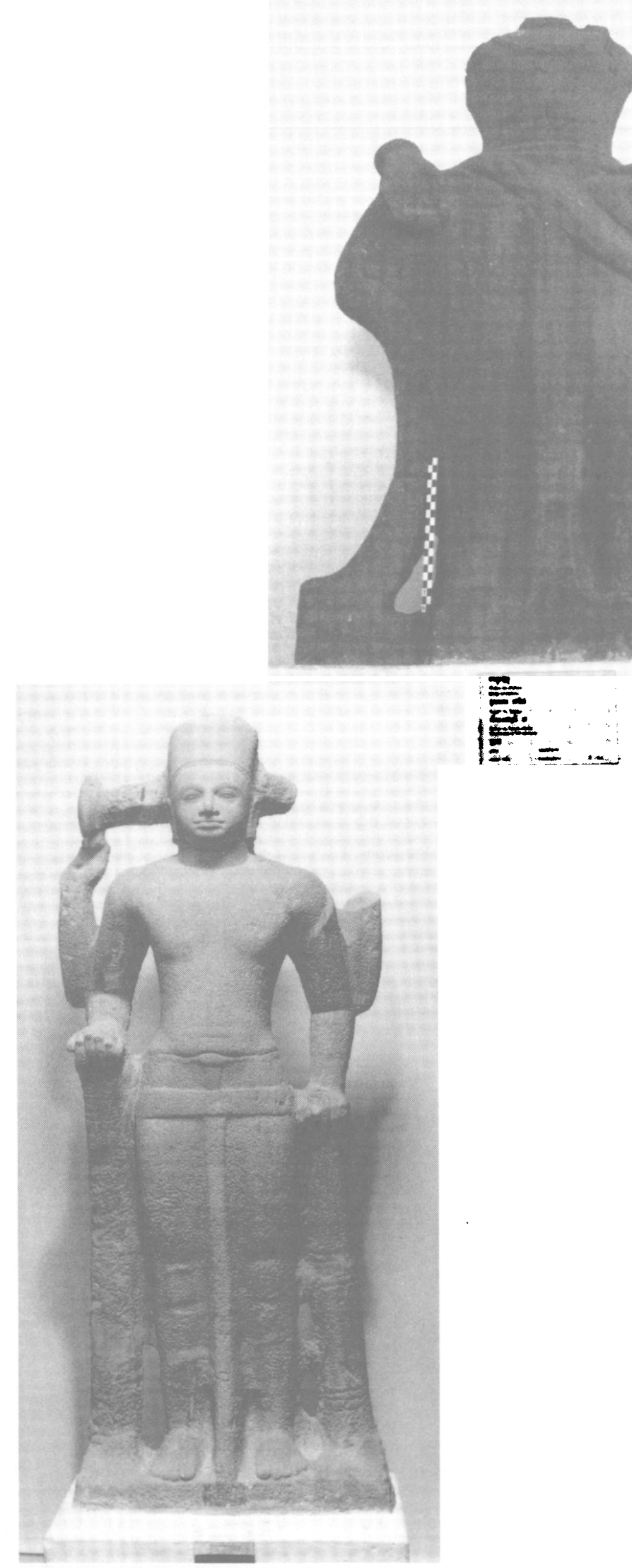

Fig. 2 : Vișnuu de Kompong Cham Kau (MNPP ; cliché EFEO).
Fig. 1 : Visnu de Tuol Koh (MNPP ; cliché EFEO).

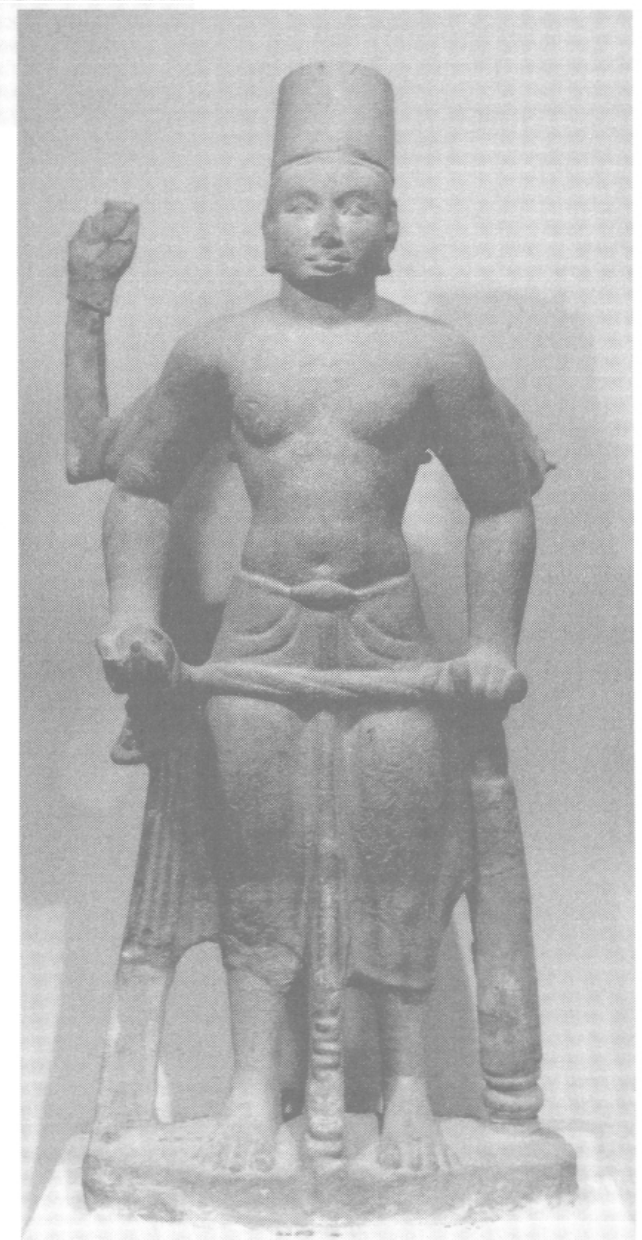

Fig. 3 : Visnu de Tuol Chuk (MNPP ; cliché EFEO). 


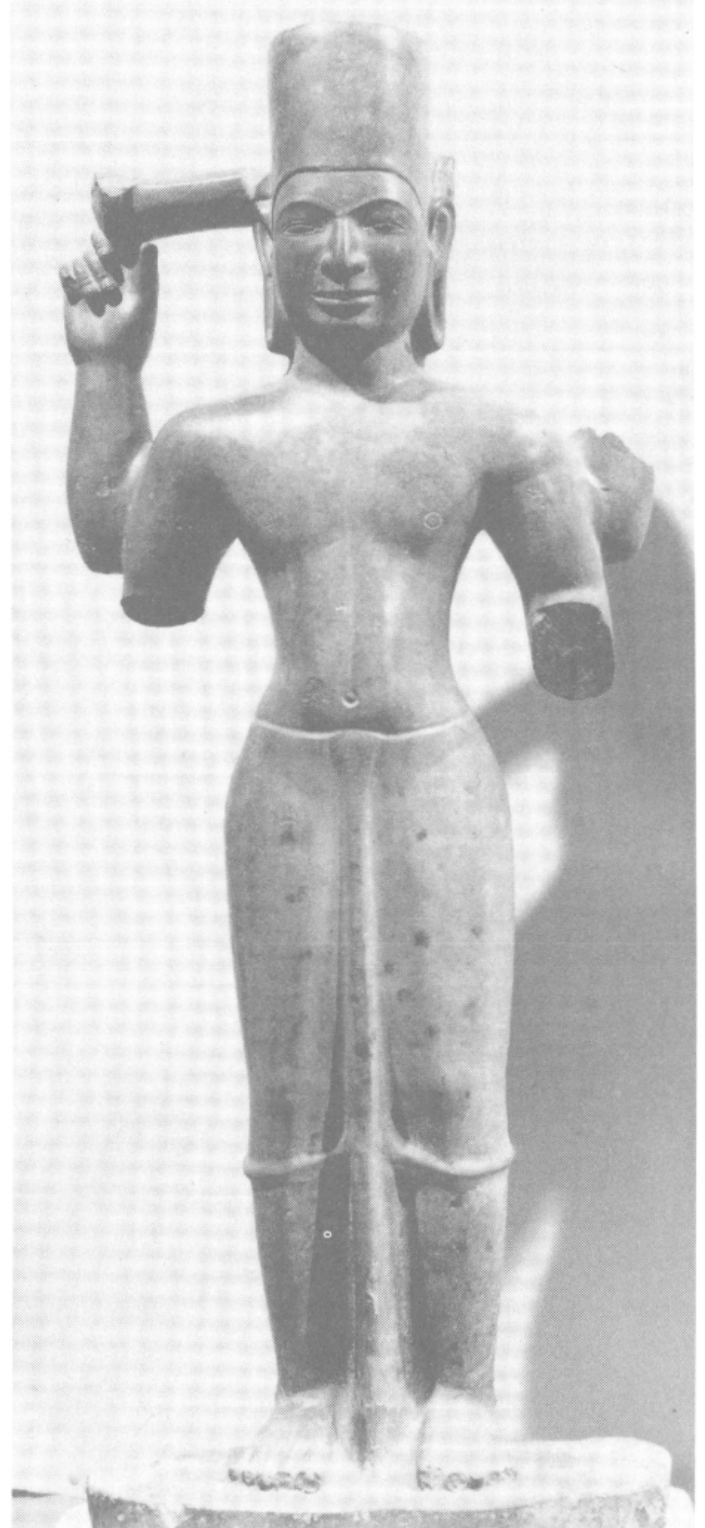

Fig. 4 : Viṣnu de Tuol Komnap (MNPP; cliché EFEO).

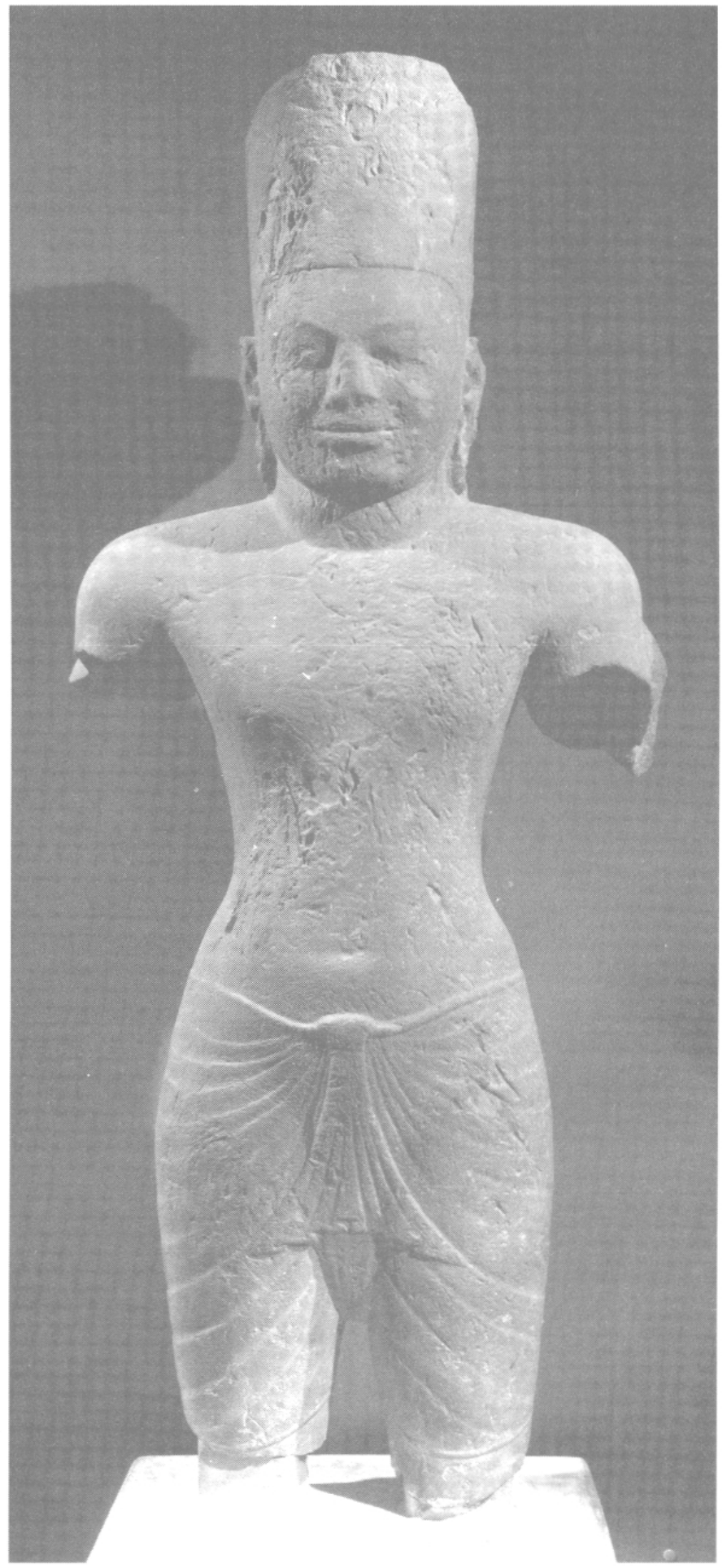

Fig. 5 : Visnu de Tuol Ang Kombot Ka, dit aussi de Chong Pisei (cliché EFEO). 


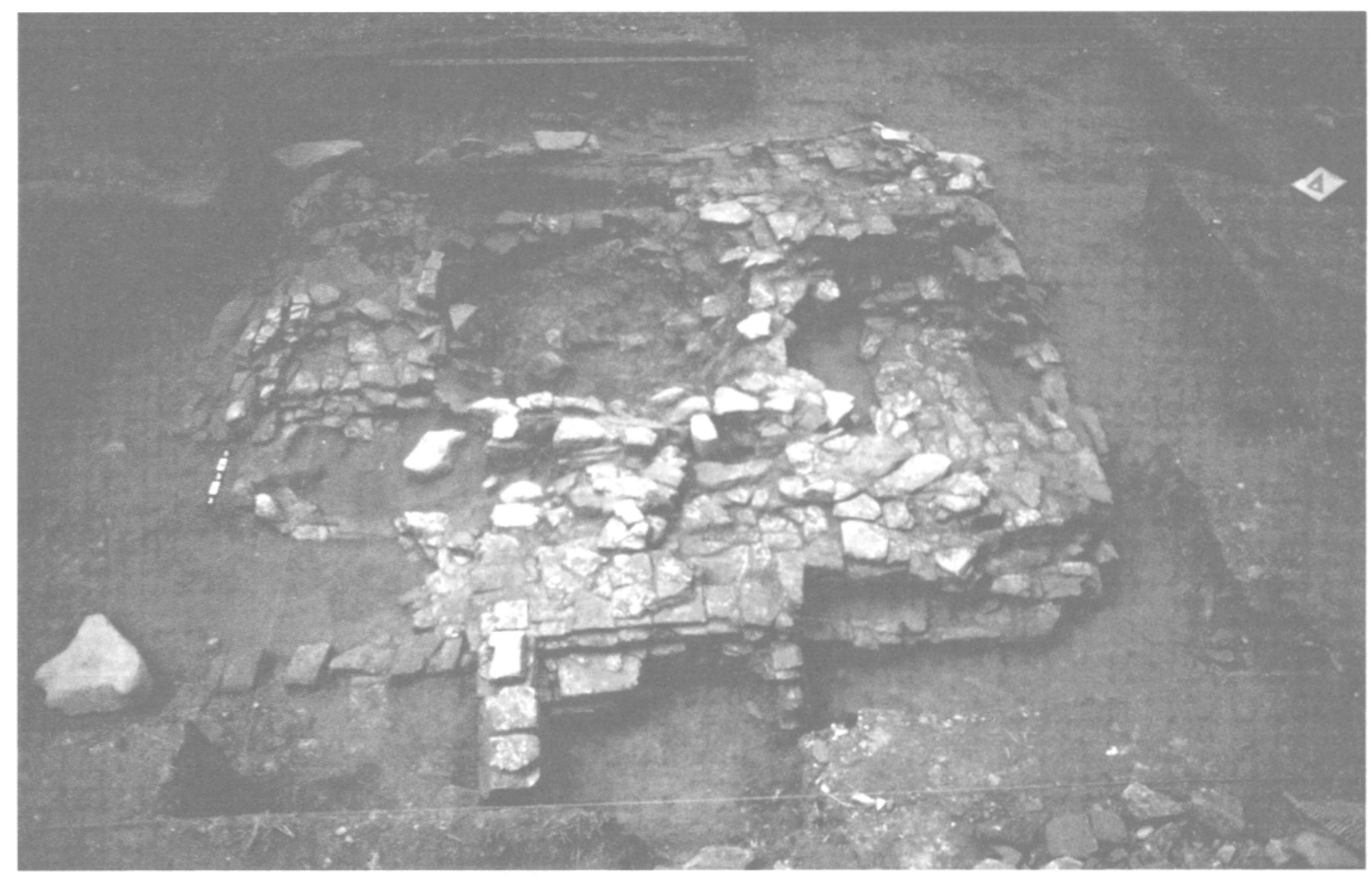

Fig. 6 : Sanctuaire vishnouite de Kota Kapur, dégagé lors de la campagne de fouilles de 1994 (l'escalier est sur la face nord) (cliché EFEO).

Fig. 7 : Fragment de corps masculin, pièce $\mathrm{n}^{\circ} 1$ de Kota Kapur (haut de $16 \mathrm{~cm}$ en l'état) (collection du Pusat Penelitian Arkeologi Nasional ; cliché EFEO).

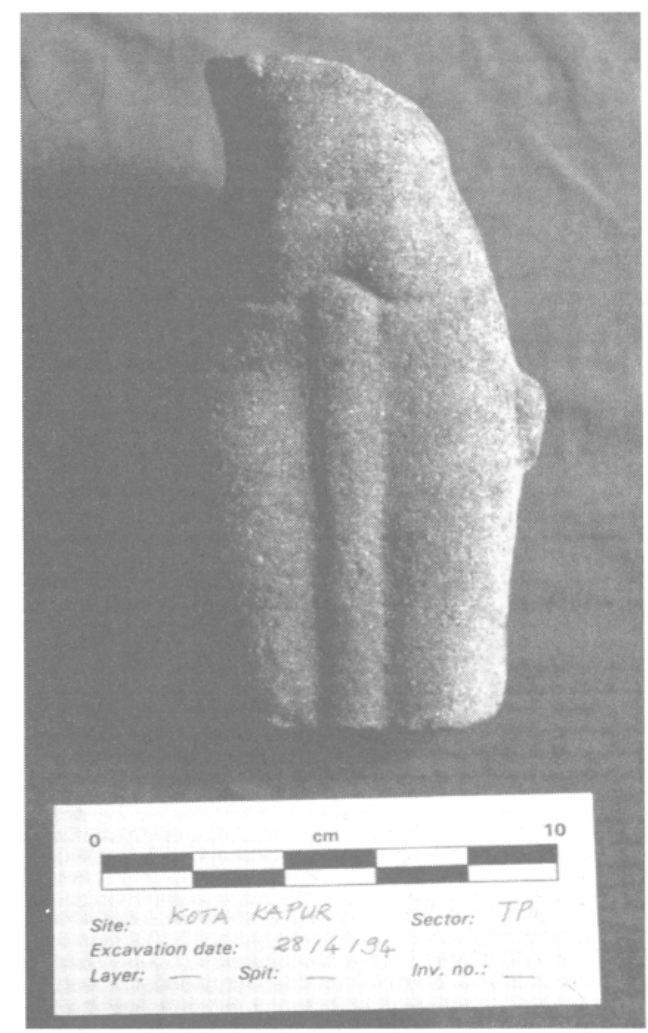




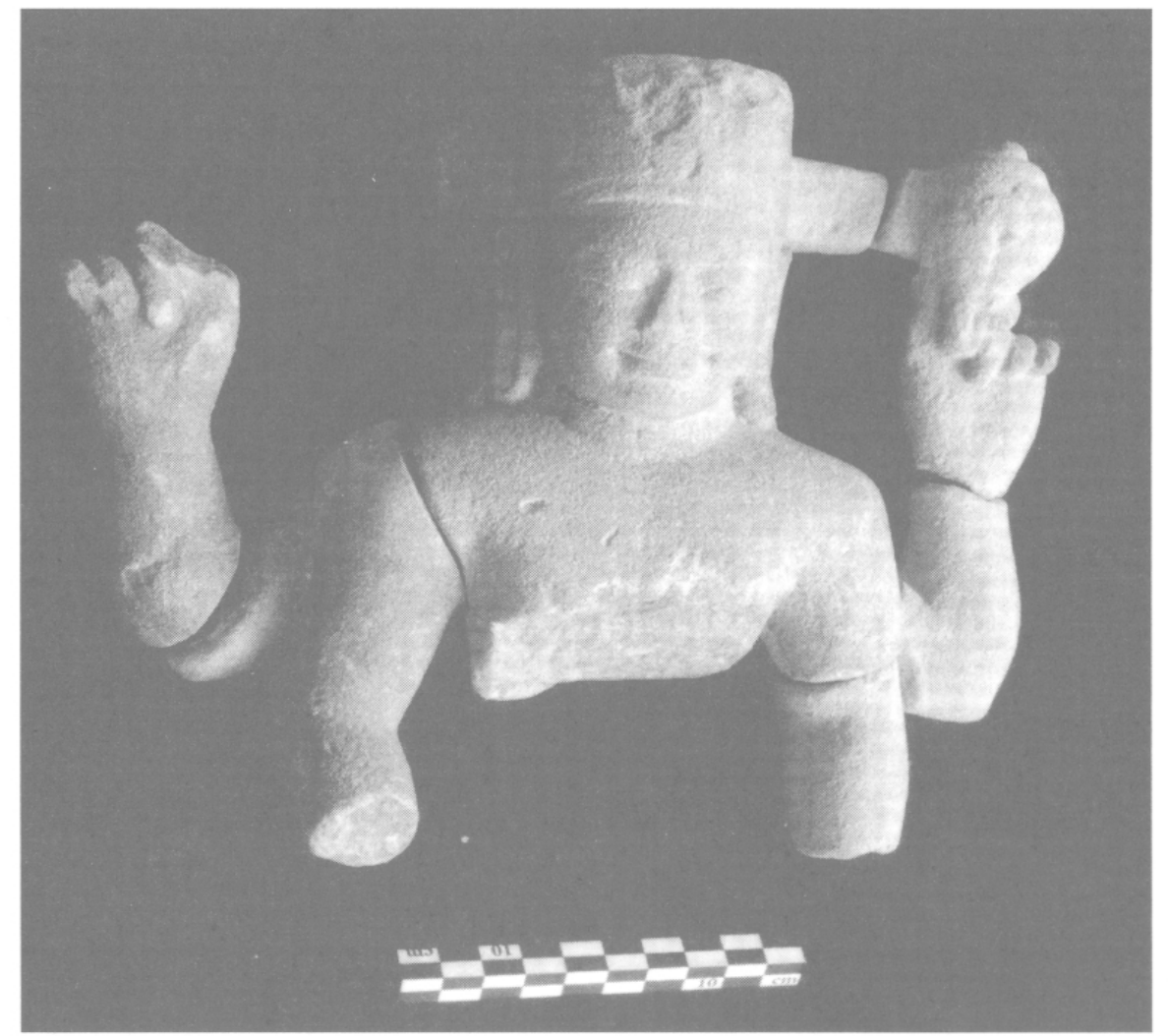

Fig. 8

Fig. 8 et 9 : Visnu $n^{\circ} 2$ de Kota Kapur (20 cm de haut, en l'état), face et dos (collection du Pusat Penelitian Arkeologi Nasional ; cliché EFEO).

Fig. 9

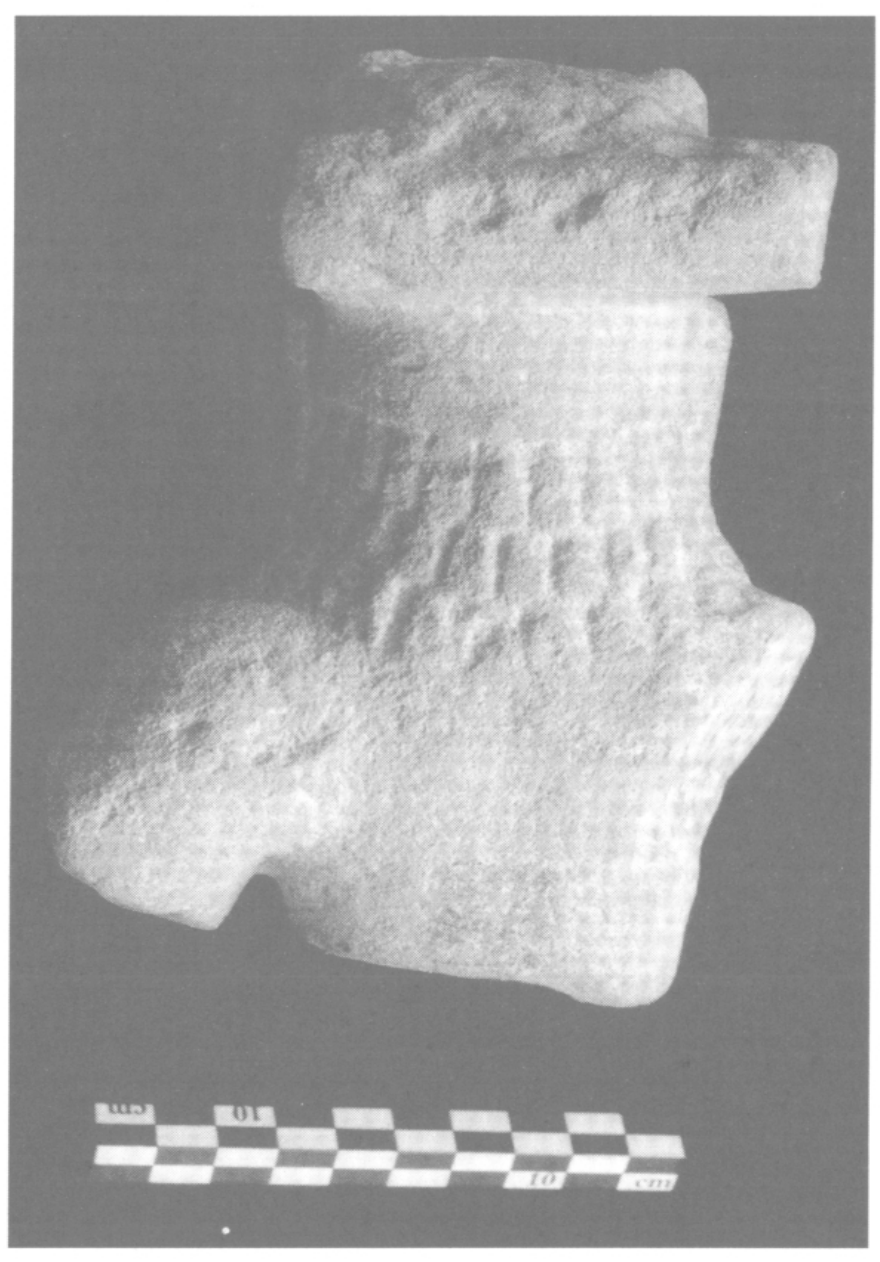




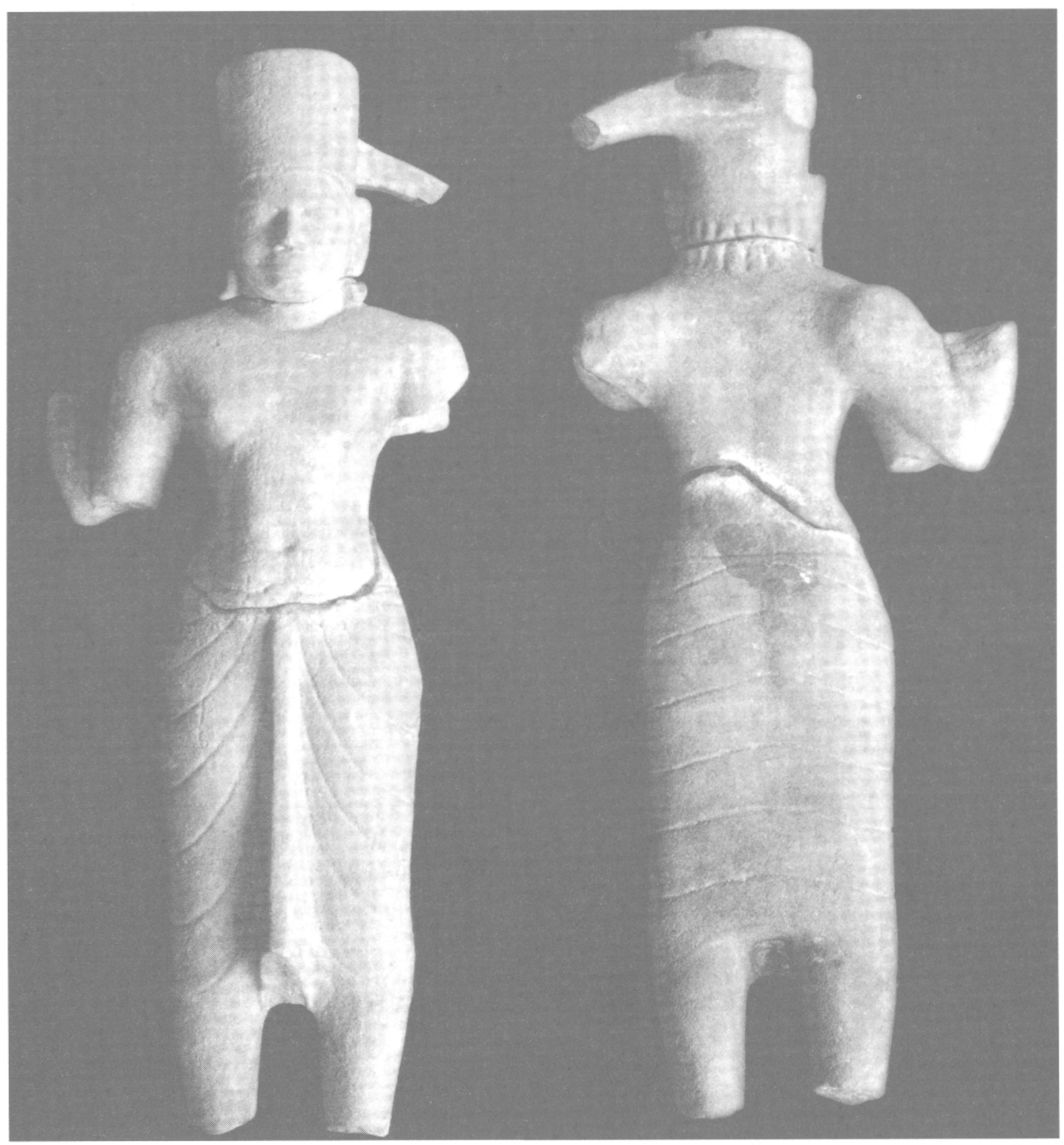

Fig. 10 et 11 : Viṣnu $n^{\circ} 3$ de Kota Kapur, face et dos $(60 \mathrm{~cm}$ de haut sans les pieds et le socle à tenon) (collection du Pusat Penelitian Arkeologi Nasional ; cliché EFEO). 


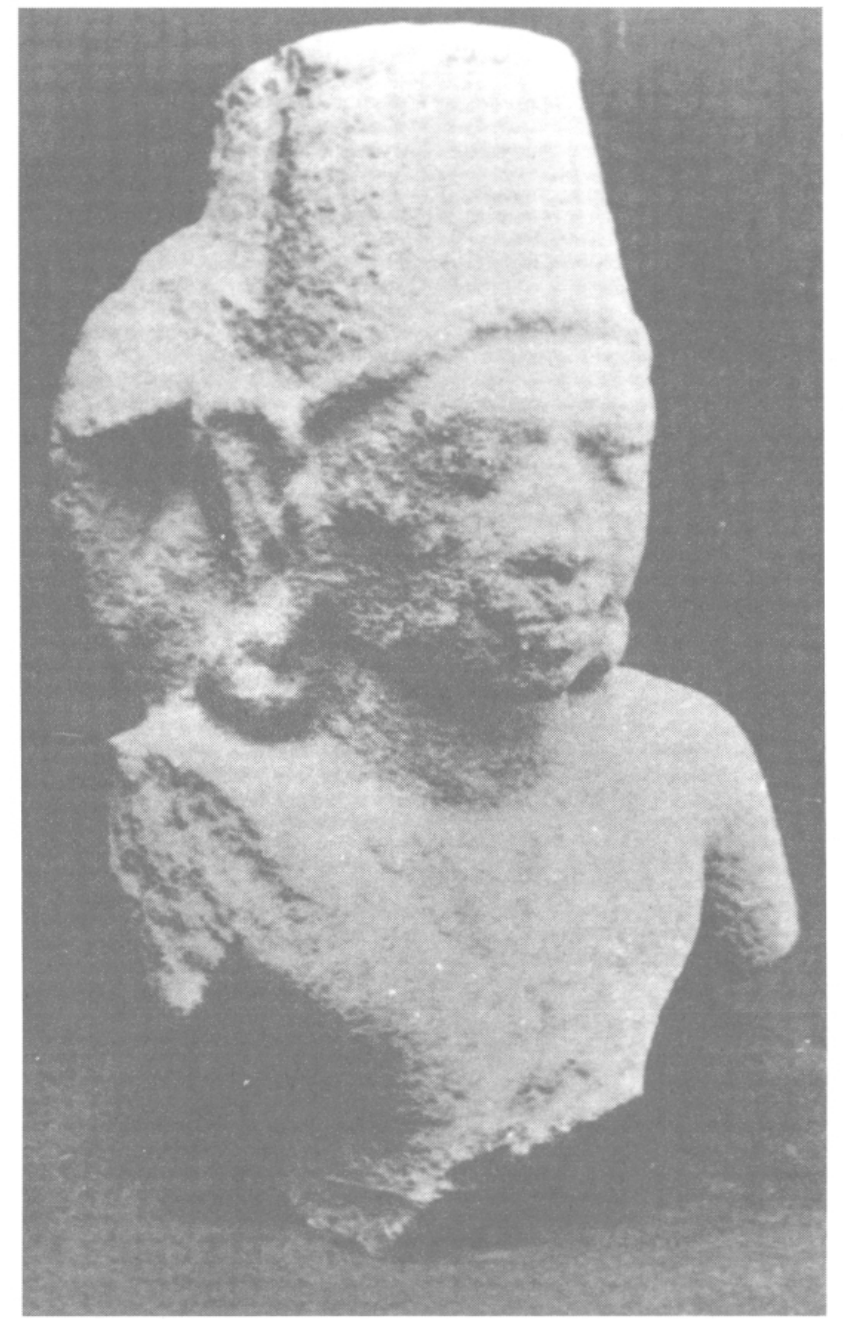

Fig. 12

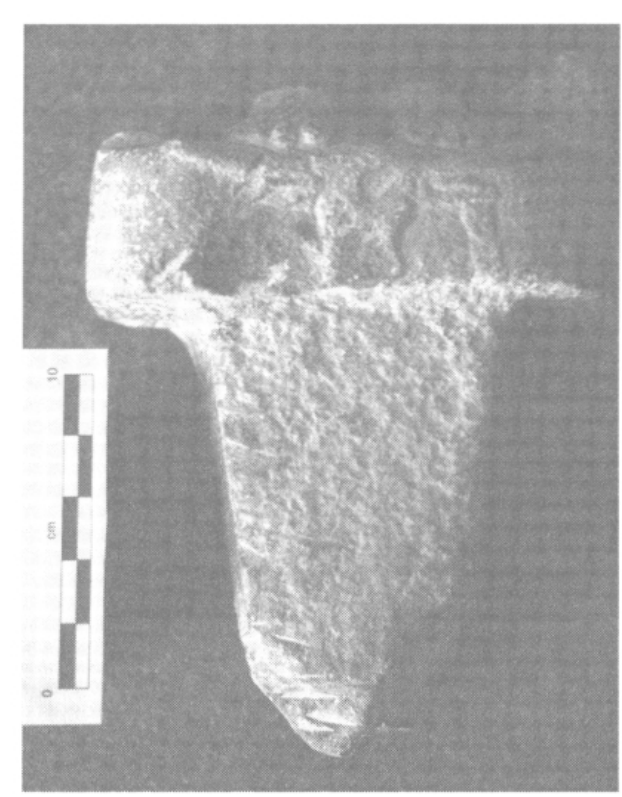

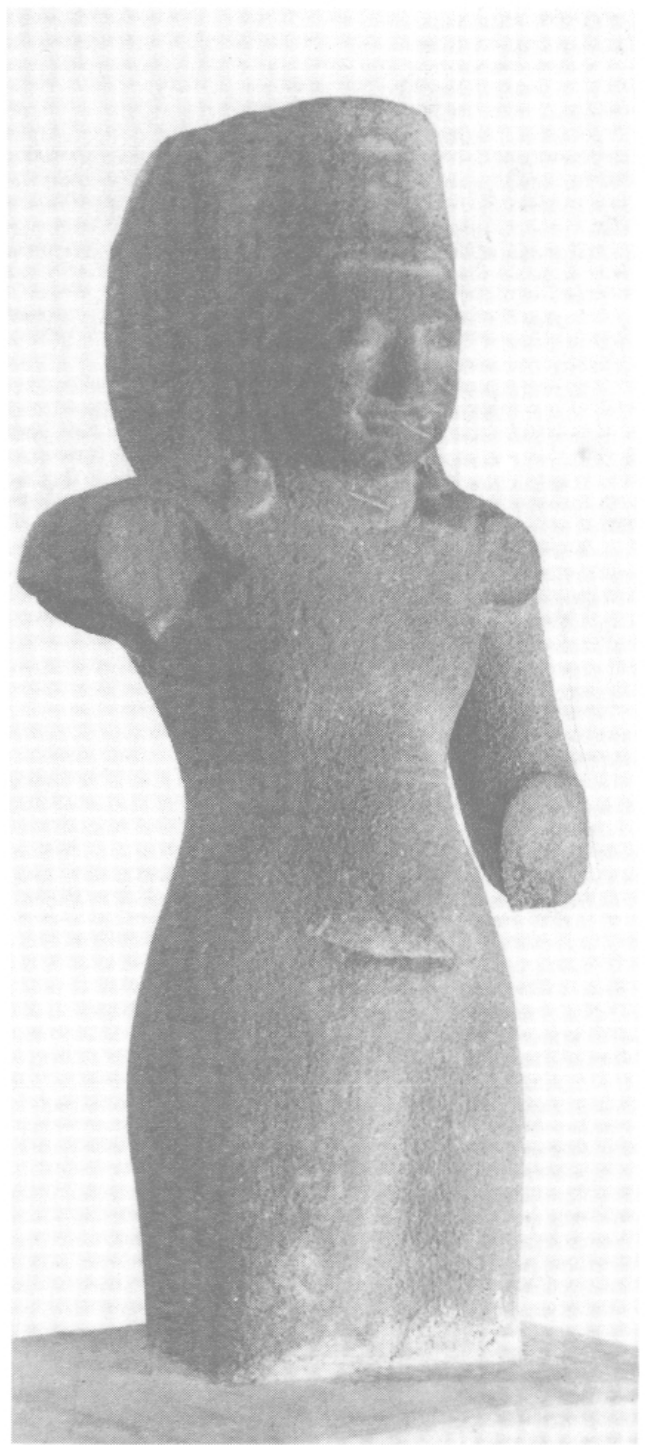

Fig. 13

Fig. 12 : Visnu (?) $\mathrm{n}^{\circ} 4$, Kota Kapur (haut de $20 \mathrm{~cm}$ en l'état) (musée national de Jakarta; photo Ouheidkundig Dienst in Nederlandsch Indië $n^{\circ} 12567$, Kern Instituut, Leiden).

Fig. 13 : Sūrya de Tiên Thuân (musée d'Histoire de Hô Chi Minh Ville; cliché EFEO).

Fig. 14 : Socle à tenon avec pieds de Durgā Mahișāsuramardinī (musée Balaputradewa de Palembang ; cliché EFEO). 

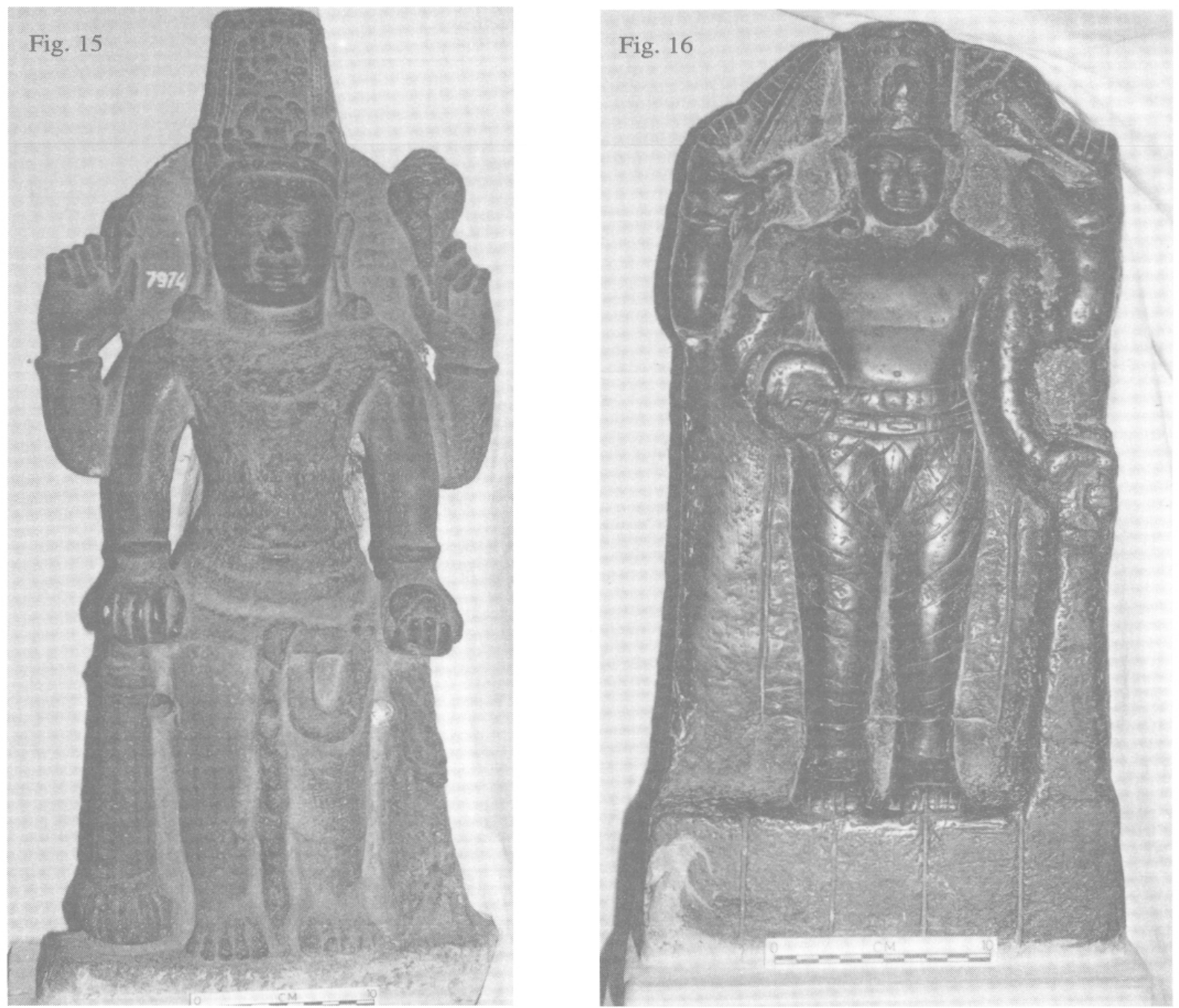

Fig. 15 : Vișnu ${ }^{\circ} 1$ de Cibuaya (musée national de Jakarta; cliché Pusat Penelitian Arkeologi Nasional).

Fig. 16 : Viṣṇu nº 2 de Cibuaya (musée national de Jakarta; cliché Pusat Penelitian Arkeologi Nasional).

Fig. 17 : Inscription sur roche de Ciaruteun (in situ, Bogor, Java Ouest ; cliché Pusat Penelitian Arkeologi Nasional).

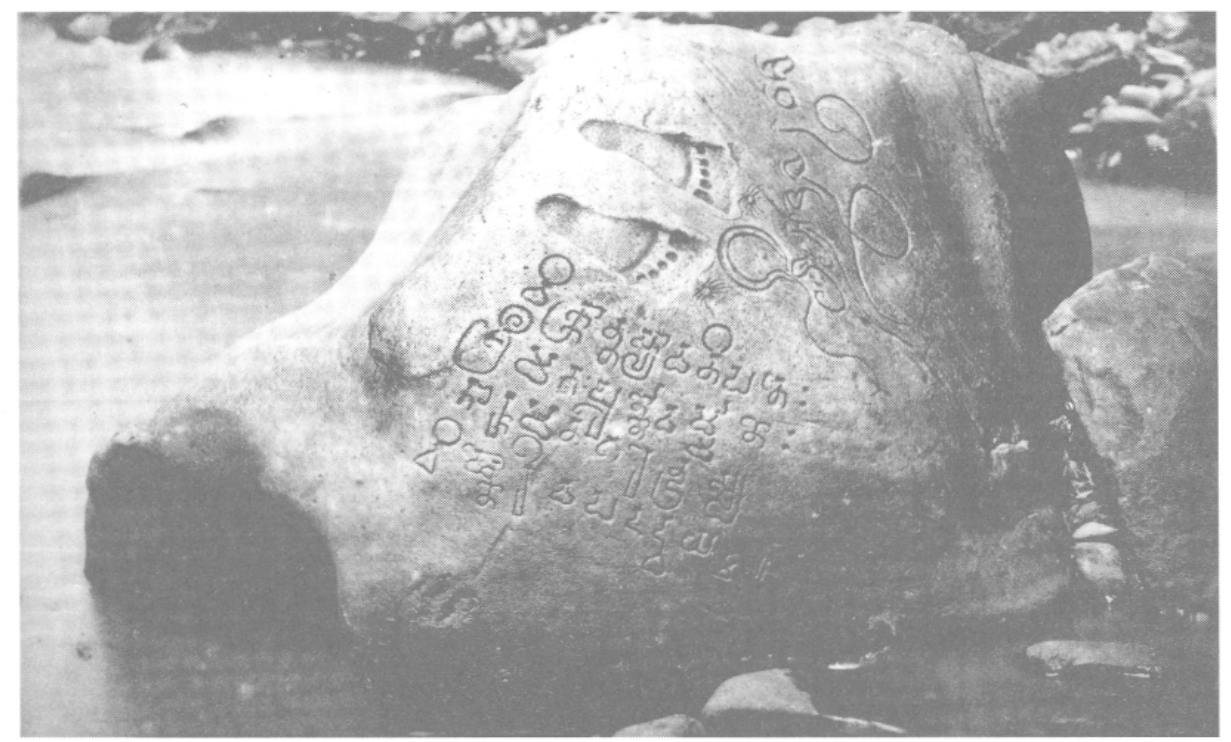

